\title{
Transplanted Neocortical Neurons Migrate Selectively into Regions of Neuronal Degeneration Produced by Chromophore-targeted Laser Photolysis
}

\author{
Jeffrey D. Macklis \\ Department of Neurology and Program in Neuroscience, Harvard Medical School, and Mental Retardation Research \\ Center, Department of Neurology, Children's Hospital, Boston, Massachusetts 02115
}

Selective degeneration of neocortical callosal pyramidal neurons by noninvasive laser illumination was used for directed studies of neocortical transplantation, to test the hypothesis that transplanted embryonic neurons may seek to restore normal cytoarchitecture within an appropriately permissive local environment. At long wavelengths that penetrate through tissue without major absorption, photolysis can cause extremely selective degeneration to desired subpopulations of targeted neurons in vivo (Macklis and Madison, 1991; Madison and Macklis, 1993). Cell death is geographically defined and slowly progressive, allowing control over the anatomical substrate for transplantation. Targeting occurs by retrograde incorporation of cytolytic chromophores that are activated by specific-wavelength light. Intermixed neurons, glia, axons, blood vessels, and connective tissue remain intact.

Degeneration was effected within neocortical lamina II/III of neonatal mouse pups following targeting in utero or early postnatally with photoactive nanospheres. Total neuron density was reduced typically by $25-30 \%$ within defined areas, with approximately $60 \%$ loss of large projection neurons and no change in the number of small, presumptive interneurons. Embryonic day 17 neocortical cell suspensions, which included recently postmitotic neurons destined to form lamina II/III, were transplanted lateral to these regions of ongoing neuron degeneration in juvenile mice. Cellular injections spanned laminae II-V, to provide donor neurons with both lateral and laminar choice for possible migration and integration. Donor cells were labeled in vitro with unique fluorescent and electron-dense nanospheres that allowed distinct identification of donor cells at both light and electron microscopic levels. Control experiments included neocortical transplants into intact age-matched hosts, into hosts with kainic acid lesions to neocortex, or distant to the region of

\footnotetext{
Received Sept. 11, 1992; revised Mar. 8, 1993; accepted Mar. 15, 1993.

This work was supported by U.S. Public Health Service Grants HD00859 and HD28478, by Mental Retardation Center Grant HD18655, and by grants from the Alzheimer's Association (IIRG-89-030) and the William Randolph Hearst Fund. I thank Tina Wilusz for excellent technical and artistic assistance; Dr. Gollu Ramamurthy for help with electron microscopy; Dr. Paul Rosenberg for generous help establishing neocortical cultures and comments on the manuscript; Dr. James Quattrochi, Dr. Evan Dreyer, and two anonymous reviewers for constructive criticism, suggestions, and comments on the manuscript; and Dr. Richard L. Sidman for helpful discussions. J.D.M. is a Rita Allen Foundation Scholar.

Correspondence should be addressed to Jeffrey D. Macklis, Enders 354, 320 Longwood Avenue, Boston, MA 02115.

Copyright @ 1993 Society for Neuroscience 0270-6474/93/133848-16\$05.00/0
}

photolytic neuronal degeneration; embryonic cerebellar transplants to the regions of selective photolytic degeneration; and grafts of hypoosmotically lysed neocortical cells to lesioned regions. After survival times of $1 \mathrm{hr}$ to 12 weeks, labeled neurons were identified morphologically and positions were digitized for qualitative and quantitative analysis of position and specificity of migration and cellular integration; electron microscopy was used to confirm further the donor identities of migrated neurons. Neurons placed near host zones of photolytic neuron degeneration migrated up to $780 \mu \mathrm{m}$ specifically within these zones; approximately $44 \%$ of donor neurons migrated significantly beyond the injection site to enter these regions. Migration and integration did not occur in normal, unaffected deeper layers IV-VI of these experimental mice, or in the normal lamina II/III bordering the transplantation site on the side opposite the neuron-deficient region. Control grafts of all five types revealed only minimal local spread without laminar preference. Donor neurons within the photolytic degeneration zones largely assumed a pyramidal neuron morphology and extended early processes; neurons outside these regions and in controls were morphologically nonpyramidal. These results suggest that transplanted neocortex seeks to restore normal cytoarchitecture in these selectively neuron-deficient zones, using age-specific cues from normal development that may be reexpressed to guide migration and integration to vacant neuronal "addresses."

IKey words: neocortex, transplantation, mouse, laser, nanospheres, lesion, graft, embryo, integration, migration, cell culture, development, degeneration, chromophore, dye, photolysis I

Significant research effort is being applied toward the transplantation of immature or genetically modified neurons to study factors critical to normal and perturbed development, and potentially to repopulate injured regions of the CNS (Gage and Fisher, 1991). Such studies of neuronal transplantation are of special relevance to potential future therapy for developmental or degenerative neocortical injury. A model system of "targeted" neuronal subpopulation injury in rodents that provides selective, defined, and localized neuronal degeneration (Madison and Macklis, 1989a,b, 1993; Macklis and Madison, 1991) now allows careful dissection of key individual effects on the migration, structural integration, and function of immature neocortical neurons transplanted into the neocortex of selectively and anatomically localized neuron-deficient hosts. 
Many studies involving the transplantation of immature neurons or genetically altered cell lines have dealt with systems in which transplanted cells might alter function or effect recovery in a relatively nonspecific, "paracrine" fashion, releasing neurotransmitters or trophic substances that can diffuse relatively long distances to reach target tissue. This is not the case for neocortex, where precise cellular circuitry is responsible for motor control, sensation, and cognition. Many studies in a variety of CNS regions indicate successful graft survival (Jaeger and Lund, 1980; Kromer et al., 1983; Nietro-Sampedro et al., 1984; Stanfield and O'Leary, 1985; Isacson et al., 1986; Gibbs and Cotman, 1987) and partial integration or functional recovery to damaged host tissue (Bjorklund et al., 1982; Freed, 1983; Gage et al., 1983, 1984; Labbe et al., 1983; Bickford-Wimer et al., 1987; Juliano et al., 1987; Buszaki et al., 1988; Goetz et al., 1989; Klassen and Lund, 1990; Lindvall et al., 1990; Liu et al., 1990; Nilsson ct al., 1990a; Ralph et al., 1990; Wictorin et al., 1990; Dawson et al., 1991). There are many questions with these models of transplantation regarding possible modes of recovery: production and passive delivery of neurotransmitters or trophic factors, surgical effects to antagonist systems, activation of endogenous host trophic factors or cellular changes, or action as a pump across the blood-brain barrier (Eclancher et al., 1985; Kesslak et al., 1986; Kromer, 1987; Rosenstein, 1987; Anderson et al., 1988; Arendt et al., 1988; Bernstein and Goldberg, 1989; Dunnett et al., 1989; Houle and Reier, 1989; Otto and Unsicker, 1990; Sofroniew et al., 1990).

Neuronal repopulation by transplantation in neocortex would require specific migration and synaptic integration of grafted cells into positions within the neuronal network left vacant by injured or degenerated neurons. These may be processes similar to those active during initial, normal neocortical development. Models for such transplantation must reflect the intricate interconnections of neurons that degenerate within cerebral cortex. Most existing models, including excitotoxic lesions, ischemic lesions, aged animals, mutant mice, and intact hosts, do not offer loss of neocortical neurons sufficiently specific to study these interactions fully (Gibbs et al., 1985; Gonzalez and Sharp, 1987; Horn and Carey, 1987; Peschanki and Besson, 1987; Hohmann and Ebner, 1988; Hugon et al., 1989; Norman et al., 1989; Sorensen et al., 1989; Tonder et al., 1989a,b).

Recent studies suggest that normal, extrinsic developmental cues are quite important in neuronal laminar "fate" determination, but that such cues are normally available only during a brief "time window" of active neuronal migration during neocortical development (McConnell, 1985, 1988; Sotelo and Alvarado-Mallart, 1986, 1987a,b; Gardette et al., 1990; Sotelo et al., 1990; McConnell and Kaznowski, 1991). Unlike neocortex, where neurons transplanted into postmigrational or nonspecifically lesioned rodents show little if any migration or integration, studies in Purkinje cell degeneration (PCD) mutant mice show a great degree of positional and temporal specificity by embryonic Purkinje cells when transplanted to adult PCD mice lacking essentially all host Purkinje cells. No neocortical, selectively neuron-deficient model exists, and nonselective lesioning methods (ischemic, excitotoxic, surgical, e.g.) do not appear to allow for such migration and integration in either neocortex or cerebellum.

The experiments reported here investigate whether immature neurons migrate correctly to their appropriate positions in regions of selective degeneration to callosal neurons in lamina II/III within postmigrational, juvenile host cortex. This approach tests the hypothesis that transplanted neocortex will seek to restore normal cytoarchitectonics within an appropriately permissive milieu. The lamina of host cortex deficient in neurons in this novel model may exert selective neurotropic action on fetal neocortical neurons, just as the Purkinje cell layer deficient in neurons in the PCD mutant is selectively repopulated after transplantation of immature cerebellum. These studies provide a model of both specificity of laminar positioning during cerebral development and potential future therapeutic transplantation. Similar paradigms could prove useful in developmental and transplantation studies involving other regions in the nervous system and other degenerative diseases. Although such experimental tissue is now primarily fetal, studies in other CNS paradigms suggest the future feasibility of using xenografts, cryopreserved cells, or cultured cells immortalized or genetically altered to retain developmental pluripotentiality (Gage et al., 1987; Lindsay et al., 1987; Fredericksen et al., 1988; Redmond et al., 1988; Rosenberg et al., 1988; Temple, 1989; Cattaneo and McKay, 1990; Horellou et al., 1990; Ronnett et al., 1990; Ryder et al., 1990; Fisher et al., 1991; Lee et al., 1991; Renfranz et al., 1991; White and Whittemore, 1991; Snyder et al., 1992).

Studies of integration by neurons of defined embryonic age into "vacant" neuronal locations within an otherwise normal environment at various developmental stages offer an in vivo three-dimensional equivalent to studies of cellular development and interaction in tissue culture. The host brain can be viewed as a custom, neurological "mutation" of precisely defined cell type, geographic location, and time after onset of neuronal degeneration. Issues of laminar commitment, cell fate, and extracellular/intracellular cues during normal developmental cell positioning can be probed in vivo by alteration of both donor cell type and host environment. Similarly, understanding the factors controlling such integration is critical to the goal of returning function by transplantation within the complex neocortex injured by a variety of dysgenetic, perinatal, or degenerative influences.

At long wavelengths in the range of $650-850 \mathrm{~nm}$, an "optical window" exists where near-infrared light energy can penetrate nervous system tissue several millimeters without significant absorption by unpigmented tissue (Anderson and Parrish, 1983; Madison and Macklis, 1989a). Selective photolysis (PL) by singlet oxygen $\left({ }^{1} \mathrm{O}_{2}\right)$ is a mechanism by which unfocused laser energy produces extremely selective, noninvasive injury to entire subpopulations of cells containing appropriate exogenously targeted photolytic chromophores with absorption in the nearinfrared range (Macklis and Madison, 1985, 1991; Madison et al., 1988; Madison and Macklis, 1989a,b). Illumination produces singlet oxygen $\left(\mathrm{O}_{2}\right)$, a toxic species with a diffusion range of approximately $0.1-0.2 \mu \mathrm{m}$. Light-activated chromophores may be targeted to specific populations of cells, producing no injury prior to specific-wavelength illumination. It is unnecessary to aim at cells to be lesioned by PL because optical and absorptive properties of target cells and neighboring tissue provide selectivity of damage. Damage by PL is different from methods using laser microbeams, fluorescent dye injections, or focused fluorescent beams (Miller and Selverston, 1979; Hibbard and Erlich, 1982; Kater and Hadley, 1982; Bently and Caudy, 1983; Raper et al., 1984; Eisen et al., 1989; Ettensohn, 1990; Jay and Keshishian, 1990). Only micrometers of tissue penetration are possible with those methods, and only small numbers of cells or localized protein are injured with individual exposures. 
Using this approach in adult mice, such cell-population-śpecific, noninvasive PL was achieved (Madison and Macklis, 1989a,b, 1993) in neocortical neurons targeted by retrograde uptake of latex nanospheres containing the chromophore chlorin $e_{6}$ in vivo, producing exquisitely selective damage to entire selected populations of callosally projecting neurons noninvasively and without damage to intermixed neurons, glia, axons, or vascular and connective tissue. This selective damage provides a defined model of neocortical neuronal deficiency seen in developmental, perinatal, or degenerative pathology. It allows control over the anatomical substrate for the study of cellular interactions after transplantation.

In the experiments reported here, embryonic day 17 (E17) neurons were transplanted into young mice with defined zones deficient in neurons within the "appropriate" lamina II/III, the layers that E17 neurons are normally "destined" to populate. The PL approach was modified for use in the early neonatal period, to produce selective neuron deficiency in juvenile mice beyond the normal migrational period, but during a period in which the normal developmental environment might be most generally permissive for repopulation, integration, and neuronal transplant viability. Immature neocortical neurons were labeled with nanospheres (Madison et al., 1990) uniquely conjugated with rhodamine $6 \mathrm{G}$ and colloidal gold prior to transplantation to allow distinct light microscopic (LM) and electron microscopic (EM) recognition of grafted cells following transplantation. Information on such integration in the neocortex provides insight into a possible hierarchy of "cues" that guide laminar positioning during development, allowing directed studies of transplantation of neocortical tissue or pluripotent neural cell lines under genetic or potentially pharmacologic control, as a possible future therapy for developmental, perinatal, and degenerative injury to neocortex.

A preliminary report of some of these experiments has been presented previously (Macklis, 1991).

\section{Materials and Methods}

This study is based on data from transplants into 97 host C57B/6J mouse pups ( 82 controls of five types, 15 experimentals), with donor neurons from 39 separate embryonic dissections ( 30 for controls and 9 for experimentals). An additional 35 mice were used to standardize the extent and progression of neocortical kainic acid lesions used for some control transplants ( $n=70$ bilateral injections), and 4 additional mice ( 2 controls and 2 experimentals) were used for glial fibrillary acidic protein (GFAP) immunohistochemistry to assess the extent of any reactive gliosis following laser photolysis. In addition to control dissociated neocortical transplants into intact hosts $(n=61)$, control neocortical transplants were performed into hosts with localized kainic acid lesions to assess potential effects on neuronal migration and integration of nonspecific host neocortical hypocellularity $(n=8 ; 16$ bilateral transplants). Control transplants of dissociated cerebellar cells were performed into hosts with regions of photolytically induced neuron degeneration to assess specificity regarding site of donor origin $(n=3)$. Hypoosmotically lysed neocortical cells were transplanted into intact hosts ( $n=2 ; 4$ bilateral transplants) and lesioned hosts $(n=4)$ to control for potential spread of intracellular label to host neurons. Controls with transplants at locations isolated from the regions of photolytically induced neuron degeneration were analyzed to assess potential nonlocalized, nonspecific effects of neuron depletion $(n=4)$. Experimental host mice were made selectively neuron deficient by targeted laser photolysis on postnatal day 4 or 5 (Fig. $1 ; \mathrm{P} 4, n=6 ; \mathrm{P} 5, n=9$ ), after unilateral cortical/callosal injection of cytolytic nanospheres in utero at embryonic day $17(\mathrm{E} 17 ; n=12)$ or on the first postnatal day (P0; $n=3)$. Cellular transplantation, using dissociated cell suspensions of embryonic neocortex or cerebellum labeled with nanospheres modified from Madison et al. (1990); allowing distinct identification by fluorescence and EM, was performed at P14-P15 in experimental mice (9-10 d after laser photolysis); at either P14-P15 or P0-P1 in intact controls; and at P14$P 15$ in kainic acid-lesioned controls (9-10 d after kainic acid injection at P4-P5), controls with transplants distant to the neuron-deficient regions, controls with cerebellar transplants, and controls with hypoosmotically lysed neocortical cells. Neocortical and cerebellar cultures from these cell suspensions were followed and assessed in parallel to the in vivo studies to assure cellular viability and differentiation. Eleven experimental mice underwent LM analysis of full series of serial sections alternately processed for fluorescence and routine histology $1 \mathrm{hr}(n=$ $2), 1 \mathrm{~d}(n=4)$, or 2 weeks $(n=5)$ later, and four underwent LM analysis (including fluorescence) of unstained thick sections only, at 1 week ( $n$ $=2$ ) or 2 weeks $(n=2)$, prior to directed microdissection and EM Control intact neonatal hosts received donor cell suspensions from three embryonic ages; 46 underwent LM analysis of full series of serial sections alternately processed for fluorescence and routine histology from $1 \mathrm{hr}$ to 12 weeks following transplantation with E13 $(n=6)$, E14/15 $(n=$ $12)$, or E17 $(n=28)$ neocortical precursor tissue. Two control intact hosts with transplanted E17 neurons were studied by directed microdissection and EM. Kainic acid-lesioned controls that received E17 neocortical transplants, E1 7 cerebellar transplant controls, hypoosmotically lysed E 17 neocortical transplant controls, and isolated location E17 neocortical transplant controls underwent analysis of full series of serial sections alternately processed for fluorescence and routine histology $1 \mathrm{hr}$ to 2 weeks following transplantation. Additional intact host controls underwent LM analysis of suboptimally fixed tissue within 1 d of transplantation, following maternally inflicted injury in the postoperative period that limited tissue fixation and integrity.

In utero and early postnatal targeting of callosal projection neurons. All $\mathrm{C} 57 \mathrm{~B} / 6 \mathrm{~J}$ mice with timed pregnancics wcre obtained from our institutional breeding colony. The day of vaginal plug observation was defined as embryonic day 0 (E0), and the day of birth defined as postnatal day $0(P 0)$. Pregnant mice at E1 7 were deeply anesthetized with Avertin and warmed throughout surgery, and the uterus exposed by a $1.5-2 \mathrm{~cm}$ midline ventral incision under sterile conditions. The embryos were externalized, typically two at a time, and three or four embryos from each litter were stabilized and injected unilaterally within deep cortex and callosum with approximately $250 \mathrm{nl}$ of nanospheres carrying chlorin $e_{6}$ (Madison and Macklis, 1989a,b, 1993), using a pulled glass micropipette with tip diameter of approximately $50 \mu \mathrm{m}$ introduced via punctate incisions in the uterus and skull made with an ophthalmic scalpel. Such injections remain extremely localized at the site of injection, providing a first level of specificity in the targeting of the desired projection population (Quattrochi ct al., 1989; Macklis and Quattrochi, 1991). Callosal ingrowth into cortical plate begins at approximately E17 in mice, so this was chosen as the earliest possible time for retrograde targeting in early experiments. Later experiments used injections made during the first postnatal day with equivalent results. Significant levels of retrograde chromophore labeling are present within a few days after injection (Katz et al., 1984). The remaining pups in utero were unmanipulated to ensure acceptance of the entire litter by the mothers after delivery. After all injections were performed, the abdomen was closed in layers with suture and the mother was allowed to recover from anesthesia over 4-6 hr of continuous warming. Mice were dropper fed a sugar/chow/water mixture during this period until fully ambulatory. They were provided such a mixture and water alone in low dishes in the cages until delivery to avoid discomfort or premature delivery.

Delivery of litters typically occurred on the expected day (E19-E20), although some litters were born up to $1 \mathrm{~d}$ early. Approximately onehalf of the injected litters survived to birth, and maternally induced injury additionally decreased survival past $1-2 \mathrm{~d}$. Approximately onethird of the injected embryos survived to be included in these experiments $(n=15)$. They were physically and behaviorally normal compared with control littermates.

Postnatal mouse pups undergoing nanosphere injection for retrograde targeting were deeply anesthetized with Avertin and warmed throughout surgery, the skin overlying the rostral skull was incised and reflected bilaterally, and nanospheres were injected as described above, approximately $1 \mathrm{~mm}$ lateral and $1 \mathrm{~mm}$ posterior to bregma. Half of cach litter was left unmanipulated to optimize maternal care to the litters. Pups were dropper fed until the entire litter was returned to maternal care.

Selective laminar lesioning. After allowing sufficient time for dense retrograde labeling of callosally projecting pyramidal neurons (Madison and Macklis, 1989a, 1993; Madison et al., 1990), P4-P5 mice were exposed to $670 \mathrm{~nm}$ laser energy transcranially over the region of homologous cortex contralateral to the initial nanosphere injection site. 
Transcranial penetration in early postnatal mice by the $670 \mathrm{~nm}$ light used in these experiments allows selective photolysis within lamina II/ III of neocortex without need for craniotomy. Mice were deeply anesthetized, and the skin overlying the rostral skull was incised and reflected bilaterally, leaving the skull intact. The site of initial nanosphere injection was identified, and the symmetrically located contralateral region was exposed to laser energy. A continuous wave solid state diode laser operating at $670 \mathrm{~nm}$ (Candela Laser Corp.) delivered $10.8 \mathrm{~mW}$ for 10 min via a 1 -mm-diameler quartz optical fiber with special optics (Candela Laser) to improve cross-sectional energy uniformity to a region approximately $2-2.5 \mathrm{~mm}$ in diameter, yielding a total incident energy density of approximately $100-150 \mathrm{~J} / \mathrm{cm}^{2}$. These optics also provide a depth of columnation limited to lamina II/III with subsequent high slope of spatial dispersion (Dang, 1990; L. C. Dang and J. D. Macklis, unpublished observations); the initially uniform column of energy scatters rapidly with these special optics at depths greater than 200-300 $\mu \mathrm{m}$, due to defocusing and tissue diffractive properties. Energy doses in lamina II/III were approximately four- to sixfold below the maximum energy dose found to cause no nonspecific injury in prior studies (Madison and Macklis, 1989a,b, 1993; Macklis and Madison, 1991). Doses in deep laminae were approximately $10-50$-fold lower than those in lamina II/III, avoiding photolysis to callosal neurons prominent in deep layers (Wise and Jones, 1976) and known to be labeled by nanospheres (Madison et al., 1990). This dosimetry was chosen to initiate a slowly progressive neuronal degeneration highly limited to callosal neurons within lamina II/III. No gross changes (erythema, e.g.) to skull or underlying brain tissue were observed. Following exposure, overlying skin was closed, and mice were returned to standard care.

Kainic acid control lesions. In a series of preliminary experiments to define appropriate conditions to induce a limited and geographically localized kainic acid lesion to neocortex, mice were injected bilaterally with kainic acid in sterile $0.1 \mathrm{M}$ phosphate buffer at $\mathrm{pH} 7.3-7.4$ at concentrations of 1 or $10 \mu \mathrm{g} / \mu \mathrm{l}$ and in volumes of $50 \mathrm{nl}$ to $1 \mu \mathrm{l}$. Appropriate, reproducible neocortical lesions approximately $1-1.5 \mathrm{~mm}$ in diameter were produced with $500 \mathrm{nl}$ and $1 \mu \mathrm{l}$ injections of $10 \mu \mathrm{g} / \mu \mathrm{l}$ solution infused into superficial to middle layers of neocortex, so these kainic acid doses were used for control transplant experiments. Lesions were apparent within the first few days; by P14-P15 lesioned areas were well dcmarcatcd and significantly hypocellular. By 1 month of age, there was significant surrounding cortical compaction to reduced thickness and relatively normal cellular density (see Fig. $6 A, B$ ).

Neonatal mice at P4-P5 were deeply anesthetized, the skin overlying the rostral skull was incised and reflected bilaterally, and a small craniotomy was performed approximately $1 \mathrm{~mm}$ lateral and $1 \mathrm{~mm}$ posterior to bregma. Pulled glass micropipettes were used to pressure inject the kainic acid solution slowly in divided volumes at four to six depths over approximately $3 \mathrm{~min}$ to minimize efflux and maximize reproducibility. Following injection, overlying skin was closed, and pups were warmed and fed until active, and returned to their litters under standard care until transplantation at P14-P15.

In vitro labeling of neurons. Embryonic neocortical cells of known gestational age (E13-E17) or E17 cerebellar cells were prepared for cell suspension transplantation injections from primary dissections of embryonic mice, using modifications of standard neocortical cell culture preparation methods (Dichter, 1978; Rosenberg and Dichter, 1989) to allow optimal neuronal dissociation, nanosphere labeling, and neuronal viability. Mixed neocortical or cerebellar cultures from each transplantation experiment were followed in parallel to the in vivo studies, using the methods of Rosenberg and Dichter (1989). Hemicortices and/or cerebellar hemispheres were dissected, detached from dura, minced, and washed three times by low-speed centrifugation and resuspension, all in calcium- and magnesium-free Hanks' buffered saline solution (HBSS-CMF; GIBCO) supplemented with glucose (4500 mg/liter), penicillin $(24 \mathrm{U} / \mathrm{ml})$ and streptomycin $(24 \mu \mathrm{g} / \mathrm{ml})$, and HEPES $(25 \mathrm{~mm})$ at $4^{\circ} \mathrm{C}$. Cells were trypsinized $(0.03 \%$ with $0.01 \%$ EDTA) for $30 \mathrm{~min}$ at $37^{\circ} \mathrm{C}$, washed in HBSS-CMF at $37^{\circ} \mathrm{C}$, and triturated in growth medium containing calcium- and magnesium-free Dulbecco's modified Eagle's medium with $4500 \mathrm{mg} /$ liter glucose (GIBCO) supplemented with HEPES (25 mM), penicillin $(24 \mathrm{U} / \mathrm{ml})$ and streptomycin $(24 \mu \mathrm{g} / \mathrm{ml})$, supplemented calf serum ( $10 \%$; Hyclone), and sodium pyruvate $(1 \mathrm{~mm})$ at $37^{\circ} \mathrm{C}$. Cells were washed again in HBSS-CMF at $37^{\circ} \mathrm{C}$, pelleted, and labeled by direct exposure to one of two nanosphere types with incorporated rhodamine $6 \mathrm{G}$ as a fluorescent label with or without colloidal gold attached (Madison et al., 1990; gifts of Prof. C. Thies, Washington University), to allow distinct LM and EM recognition of transplanted

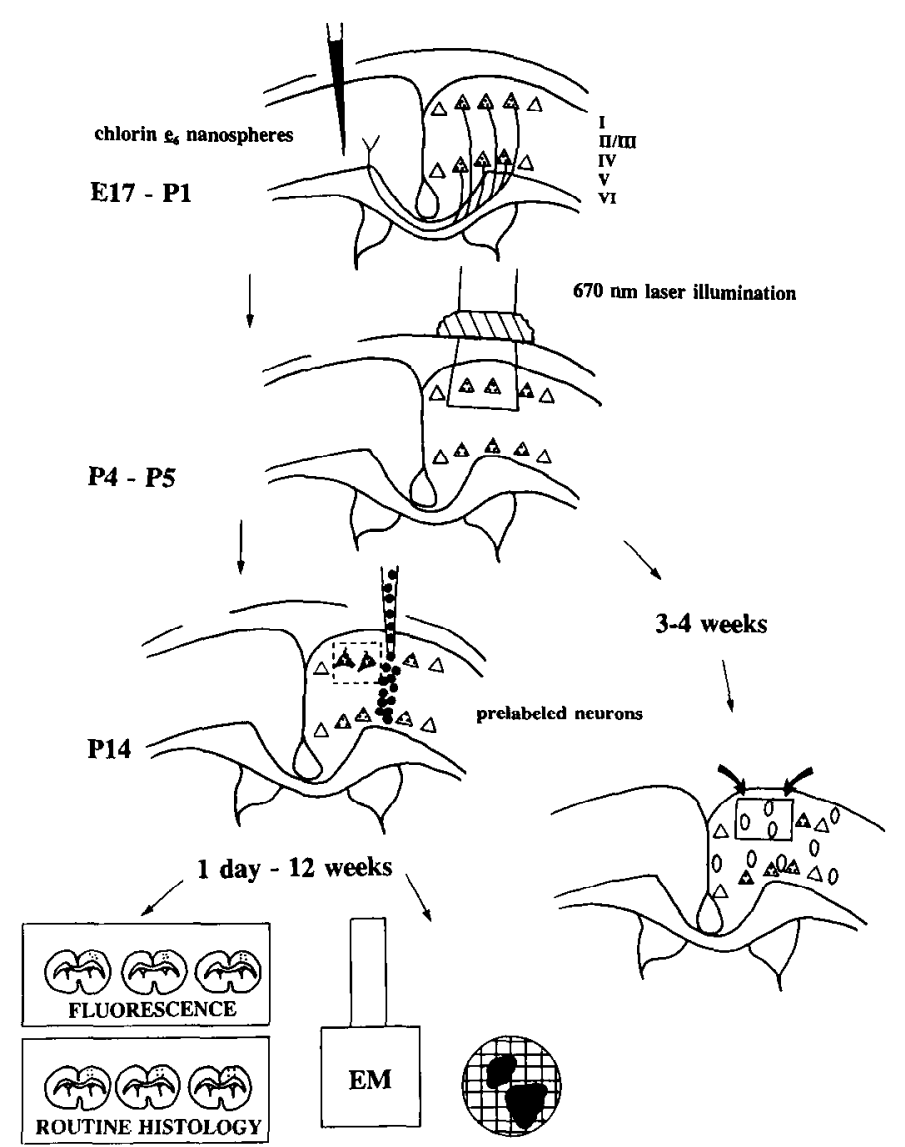

Figure 1. Schematic representation of sequential steps in preparation of zones of photolytic pyramidal neuron degeneration for experimental neocortical cell transplants. Photoactive nanospheres were injected unilaterally via a pulled glass micropipette either at EI 7 in utero or at $\mathrm{P0}$ Pl $(t o p)$. After uptake by axonal terminals and retrograde labeling of callosally projecting pyramidal neurons (dotted pyramids in laminae II/ III and V), P4-P5 mice were exposed to $670 \mathrm{~nm}$ laser energy transcranially via a quartz fiber optically coupled to the skull by saline (hatched area) over the region of homologous cortex contralateral to the initial nanosphere injection site. Energy dosimetry was selected to initiate progressive, noninflammatory neuronal degeneration to labeled neurons slowly within lamina II/III of the exposure field. Neocortical cell suspensions, with neurons prelabeled with distinct nanospheres providing identification by fluorescence and EM, were transplanted on PI4 spanning laminae II-V adjacent to these zones (outlined box containing jagged pyramids representing degenerating neurons). Labeled neurons outside the defined zone of laser illumination remain undamaged. In the absence of repopulation by transplantation, these zones become specifically deficient in pyramidal ncurons, without change in the population of smaller interneurons (ovals). Histologic and ultrastructural analyses of donor neuron migration and integration were performed in experimental and control mice from $1 \mathrm{hr}$ to 12 weeks after transplantation.

cells. Nanospheres were diluted and added to the cell pellet to a final dilution of approximately $1: 30 \mathrm{v} / \mathrm{v}$ for $30 \mathrm{~min}$ at room temperature with intermittent gentle trituration. Labeled cells were washed three times with HBSS-CMF at $4^{\circ} \mathrm{C}$, pelleted to a final concentration of $5 \times$ $10^{4}$ to $1 \times 10^{5} \mathrm{cells} / \mu \mathrm{l}$, and stored at $4^{\circ} \mathrm{C}$ during the multiple cell injections. Viability as assessed by the exclusion of trypan blue was typically approximately $75 \%$. Neocortical cells to be hypoosmotically lysed as controls underwent their final wash, pelleting, and storage in sterile distilled water.

Aliquots at each stage of each neocortical or cerebellar dissection were followed for approximately 2 weeks to ensure neuronal labeling and viability. Samples were taken prior to labeling, after labeling, and from the glass micropipette tip after each cellular injection. Labeling was relatively specific for neurons as identified morphologically by phase- 
contrast illumination as described previously, with neurons displaying distinct, punctate granular fluorescence and glia largely unlabeled (Madison et al., 1990; Macklis and Madison, 1991). Although useful, this specificity was not essential to interpretation of the studies, as identities of labeled neurons were confirmed morphologically. Neuronal viability was excellent, equivalent between labeled neurons, prelabeled aliquots, and control cultures prepared by standard methods within this department (Rosenberg and Dichter, 1989).

Neuronal transplantation. Mice were deeply anesthetized, and the skin overlying the skull was incised and reflected bilaterally to reveal the original chlorin $e_{6}$ nanosphere injection site and laser-illuminated contralateral homologous cortex. A small craniotomy was performed immediately lateral to the region of laser exposure, exposing the dura. Cell suspensions were slowly pressure injected via pulled glass micropipettes with tip diameters of approximately $100 \mu \mathrm{m}$, in a "tubular" distribution spanning the thickness of neocortex from layer $V$ to layer $11 / 111$, using a modified stereotaxic approach to inject $50 \mathrm{nl}$ at each of five depths spaced $50 \mu \mathrm{m}$ apart, withdrawing slowly between injections and after the final injection to provide maximum cellular retention and reproducibility of transplant location and volumes, minimizing tissue disruption. Typically, the location of cellular injection was approximately 1-2 $\mathrm{mm}$ lateral and $1-2 \mathrm{~mm}$ posterior to bregma, guided by the location of prior laser illumination. Overlying skin was closed, and mice were returncd to normal carc until histological analysis. Because there is no wound as seen following surgical preparations for grafting, and because prior studies in adult mice (Macklis and Madison, 1991; Madison and Macklis, 1989a,b; R. D. Madison and J. D. Macklis, unpublished observations) have revealed no significant gliosis or inflammatory reaction, there is no inherent need for delay between laser photolysis and cellular transplantation. We waited $9-10 \mathrm{~d}$ to ensure active, ongoing neuronal degeneration, based on prior findings of the time progression of neuronal injury as seen by routine histology and silver degeneration staining.

Histological analysis. Survival times for histological analysis ranged from 1 hr to 12 weeks following neocortical cell suspension transplantation into control mice; experimentally laser-treated mice were evaluated between $1 \mathrm{hr}$ and 2 weeks after receiving transplants. Mice undergoing LM and fluorescence analysis without EM analysis were deeply anesthetized with Avertin, transcardially perfused with $2 \%$ paraformaldehyde (to minimize autofluorescence) in a $0.1 \mathrm{M}$ phosphate buffer (pH 7.3-7.4), and postfixed overnight in the same fixative. These brains were blocked for coronal sectioning through the regions of laser exposure and cellular transplantation, and serial sections $40 \mu \mathrm{m}$ thick were cut on a vibrating microtome. Alternate sections were processed and mounted for fluorescence (two of three) and either cresyl violet (CV) or hematoxylin and eosin (H\&E) to assess cellular morphology, spread from the radially oriented injection site, and possible histologic integration. Fluorescence sections were cut, air dried on albuminized slides, dehydrated by brief exposure to graded ethanol, cleared in methylsalicylate, quickly dipped in xylenes, permanently mounted in Fluoromount (Gurr), and examined with a Zeiss microscope equipped with epifluorescence (Axioskop). Initial low-magnification analysis was performed by two observers on each section in a blinded fashion, generating camera lucida representations of each $\mathrm{CV}$ - or H\&E-stained section, on which the positions of fluorescently labeled donor neurons were indicated from adjacent fluorescence sections. Higher-magnification phase contrast and fluorescence microscopy were used to differentiate transplanted neurons from non-neuronal cells by morphologic criteria, and to confirm donor identities of uniquely labeled neurons. Neuronal viability, morphology, migration from the tubular injection site, laminar distribution, and gross histologic integration were assessed in all mice.

The positions of fluorescently labeled donor neurons were manually digitized from camera lucida drawings ( $n=18$ from controls, 15 intact, and 3 kainic acid lesioncd, spanning 4056 labeled donor neurons; $n=$ 6 from experimentals at 2 weeks, spanning 1521 labeled donor neurons) for quantitative analysis of neuronal migration in the control cases with maximal neuronal dispersion and in experimental cases at 2 weeks. A computer-based image analysis system (JAVA, Jandel Scientific) was used to determine absolute distances and variability of spread in experimental and control mice, the number and proportion of transplanted neurons spreading significantly laterally (beyond three standard deviations of controls), and the directional specificity of neuronal spread (into the region of neuronal degeneration or toward the opposite side of the injection site).

Quantitative analysis of the extent and morphologic specificity of neuronal injury within the zones of selective laser photolysis was performed in experimental cases in which the zone of neuronal depletion extended more than $120 \mu \mathrm{m}$ rostral or caudal to the region repopulated by cellular transplantation $(n=4)$. Such an "offset" occurred when the cellular injection site was not precisely lateral to the region of neuronal depletion. This allowed adequate sampling of multiple stained sections in these cases. The JAVA image analysis system, along with simultaneous direct microscopy, was used to sample multiple regions of defined size within the laser photolysis zone, in immediately adjacent ipsilateral control zones both medial and lateral to this region, and in contralateral symmetrically homologous cortex. Neurons were counted by standard criteria to obtain absolute numbers in all focal planes, in each of six experimental zones and 18 control zones ( 6 ipsilateral medial, six ipsilateral lateral, six contralateral) for each case. Neuronal outlines were manually digitized to compute individual neuronal cross-sectional areas in each of these 24 zones for each case, using a randomizing grid to sample 16 neurons per $5000 \mu \mathrm{m}^{2}$ zone. Neuron counts and area measurements were repeated by the initial observer and by a blinded second observer on selected zones from these four cases to assess both reproducibility of measurements by a single observer and interobserver reliability.

Mice undergoing combined LM and EM analysis were processed differently, to allow further identification of transplanted neurons labeled with electron-dense nanospheres coated with colloidal gold, while minimizing autofluorescence that occurs with full EM fixation. Mice $(n=$ 6) were deeply anesthetized and transcardially perfused with $4 \%$ paraformaldehyde and $0.5 \%$ glutaraldehyde in phosphate buffer. Brains were removed, blocked, and postfixed overnight in the same fixative. Sections $250 \mu \mathrm{m}$ thick were cut on a vibrating microtome, cellular fluorescence was observed at low magnification in wet mounts, and regions containing transplanted neurons were microdissected into PBS with 20\% sucrose. These regions of interest were osmicated, dehydrated in serial ethanol grades, and embedded, and sections were stained with uranyl acetate and lead citrate. Sections were observed by EM at low magnification to assess the ease of rapid, distinct identification of donor neurons labeled with these nanospheres that both withstand EM processing solvents and are coated with colloidal gold particles. Higher-magnification analysis was used to confirm and localize the labeling. Because the EM analysis was performed only 2 weeks after cellular transplantation, no scrial rcconstruction or further dirceted ultrastructural analysis (for synaptic specializations, e.g.) was performed on this tissue.

Immunohistochemical staining for GFAP was performed using a commercially available, polyclonal antiserum (rabbit anti-GFAP, Incstar) and the peroxidase-antiperoxidase (PAP) method. Two experimental mice were targeted for selective photolysis to callosally projecting pyramidal neurons at P1 by injection of photoactive nanospheres, and neuronal injury was effected by exposure to $670 \mathrm{~nm}$ laser energy at P14, as described above for in utero targeting. Processing for GFAP immunohistochemistry was performed 2 and 3 weeks later, corresponding to the time in transplanted experimental mice of cellular transplantation and early integration 1 week later, respectively. Two control mice underwent unilateral micropipette injections and were processed for GFAP staining $1 \mathrm{~d}$ later, to provide "positive control" staining at the injection site and "negative control" tissue contralaterally. Mice $(n=4)$ were anesthetized and perfused as described above, sections were cut $30 \mu \mathrm{m}$ thick on a vibrating microtome, and processing was performed in phosphate-buffered saline (PBS) on slides. Sections were preblocked with $10 \%$ sheep whole serum in PBS for $15 \mathrm{~min}$ at room temperature, exposed to undiluted primary antiserum for $20 \mathrm{~min}$ at room temperature, washed twice with PBS, exposed to sheep anti-rabbit IgG (Cappell) diluted 1:70 in PBS for 30 min at room temperature, washed twice with PBS, exposed to rabhit PAP (Cappell) diluted 1:500 for $30 \mathrm{~min}$ at room temperature, washed twice in PBS, and developed using freshly prepared diaminobenzidine with hydrogen peroxide in PBS. Slides were analyzed unmounted, and then sections were dehydrated in graded ethanols, briefly cleared in xylenes, permanently mounted in Permount (Fisher), and reexamined at higher magnification. Omission of the primary antiserum eliminated the GFAP staining in the "positive controls," pretreatment with hydrogen peroxide to eliminate endogenous peroxidase did not alter the "positive control" staining at the micropipette injection site, and permeabilization with Triton $\mathrm{X}-100$ did not enhance otherwise negative staining.

\section{Results}

Sections rostral or caudal to the area of cellular transplantation displayed geographically defined loss of larger-diameter mor- 

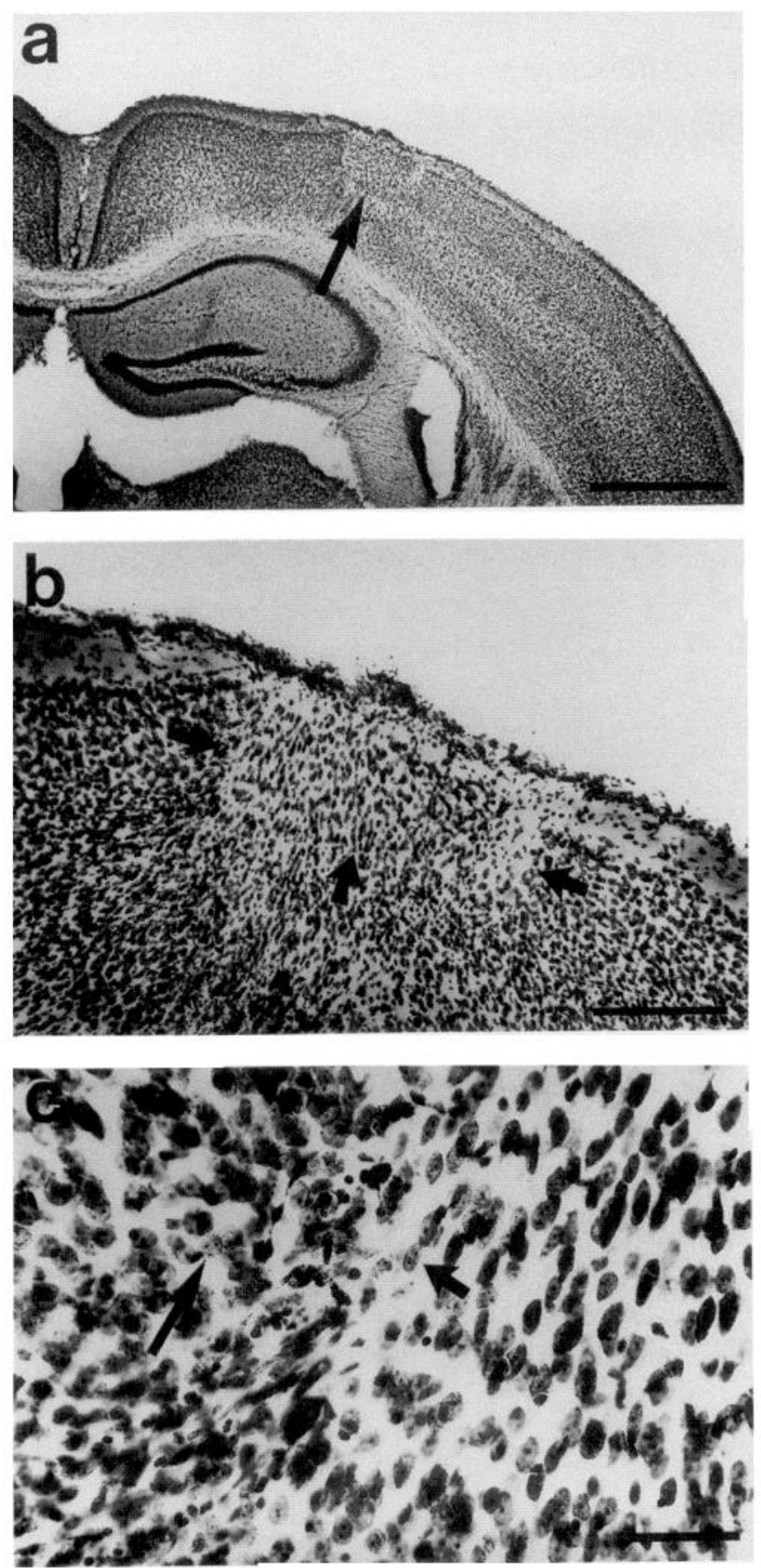

Figure 2. Selective lesioning by PL of large, retrogradely targeted, pyramidal neurons in lamina II/III of neocortex indicated by absence of these large-diameter neurons and relative neuron deficiency within the well-demarcated region indicated by arrows in $a$ and $b$. $c$, Higher-magnification view of this CV-stained section, with relative absence of pyramids to the right of the long arrow, and remaining population of smaller-diameter, ovoid, presumptive local-connection neurons (short arrow). Staining for GFAP did not reveal significant reactive gliosis, and no significant inflammatory infiltration occurred. Scale bars: $a, 1$ $\mathrm{mm} ; b, 250 \mu \mathrm{m} ; c, 50 \mu \mathrm{m}$.

phologically pyramidal neurons within rectangular regions approximately 500-600 $\mu \mathrm{m}$ wide and spanning the thickness of neocortical lamina II/III (Fig. 2). Within these regions of overall neuron deficiency, the remaining population was predominantly of smaller, ovoid, presumptive local connection neurons. These zones correspond well in size and localization to the zones in
A

$\square$ IPSILATERAL \& CONTRALATERAL CONTROL REGIONS
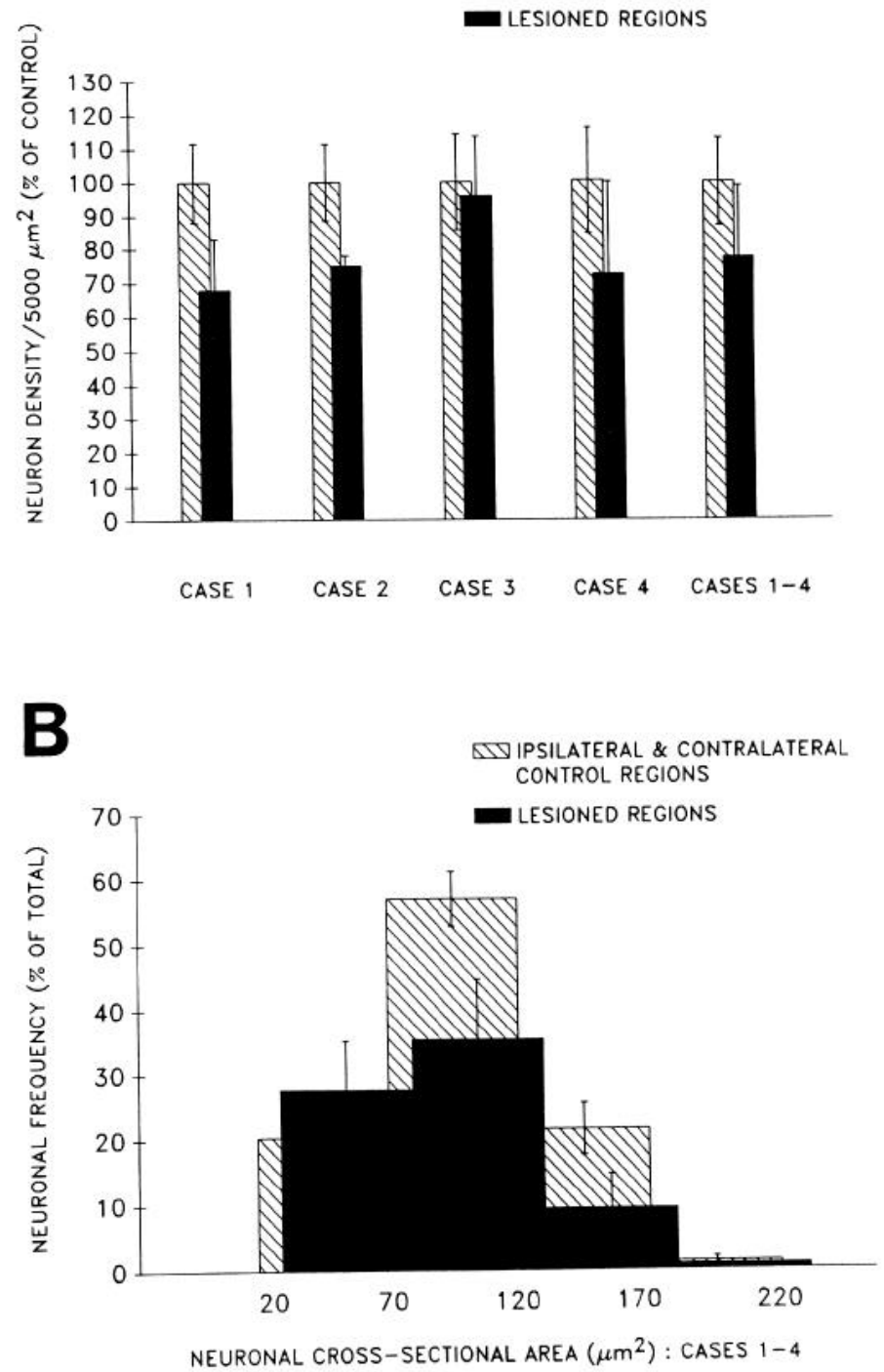

Figure 3. A, Quantitative neuron density within lesioned zones and in adjacent and contralateral homologous zones for four experimental cases $(n=18$ sample control zones and $n=6$ sample lesioned zones quantified per case; error bars represent SD). $B$, Quantitative neuronal cross-sectional areas for the four cases in $A$, demonstrating relative loss of large-diameter pyramidal neurons, without change in the population of smaller-diameter, presumptive interneurons $(n=72$ control zones and $n=24$ experimental zones; error bars represent SD).

lamina II/III seen previously in adult mice and rats in which degeneration of callosally projecting pyramidal neurons was revealed by silver degeneration staining (Madison and Macklis, 1989a,b, 1993). There was no injury visible to overlying layer I, or to underlying or surrounding regions of cortex. No significant inflammatory reaction was visible by routine $\mathrm{H} \& \mathrm{E}$ histology; there was no inflammatory infiltrate or increased cellularity, and only rare macrophages were seen. Staining for GFAP immunoreactivity was unchanged compared with controls. It was absent in the regions of neuronal depletion and intact normal cortex, and it showed only labeling of rare callosal astrocytes.

Quantitative morphometric analysis of these zones revealed reduction of total neuron number by $5-32 \%$, typically $25-30 \%$, compared with adjacent and contralateral homologous control 

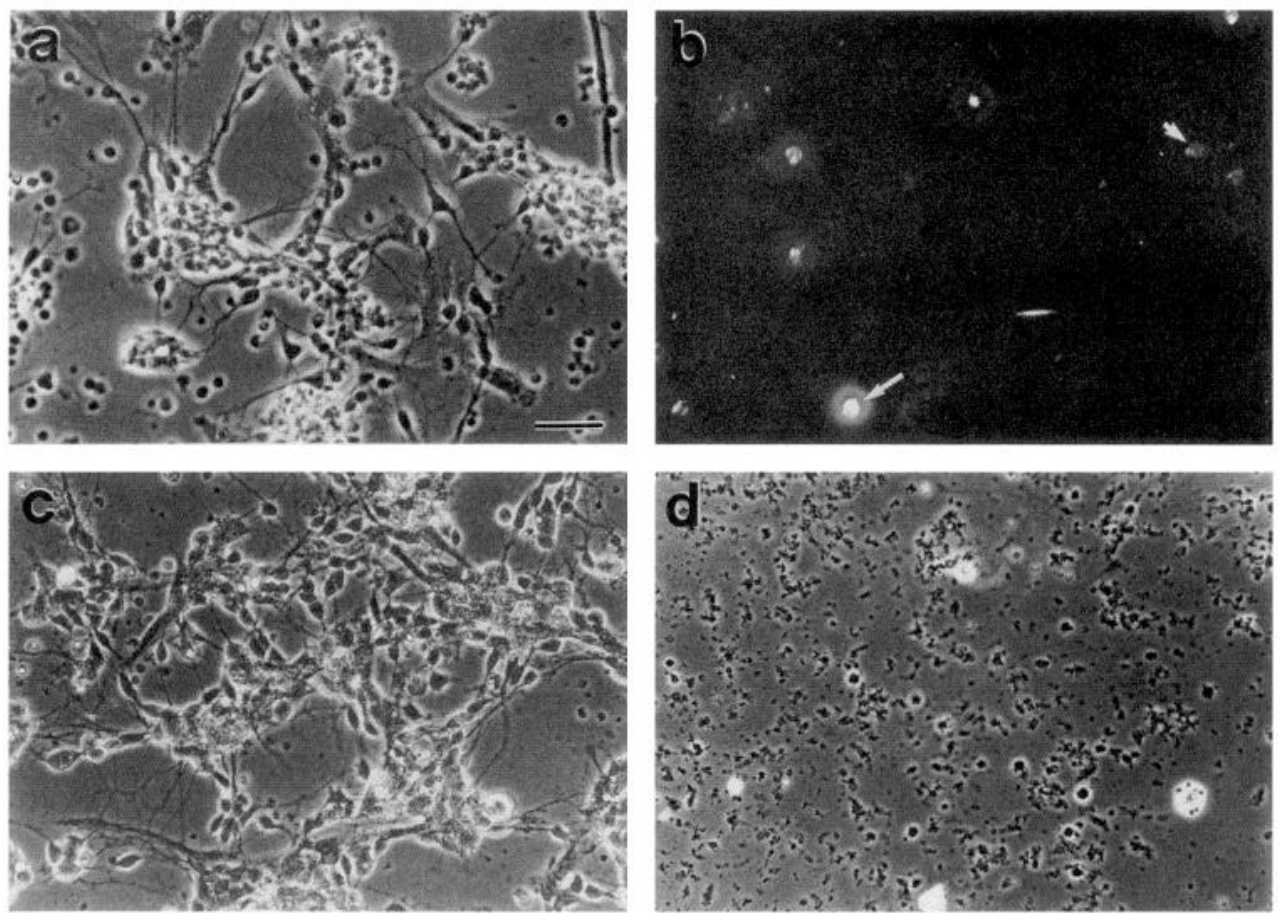

Figure 4. Cultures of transplanted donor cells followed in parallel to the in vivo transplantation experiments. Embryonic neocortical or cerebellar cultures were plated from the pulled glass micropipettes used for cellular injection into neocortex, and at earlier stages of the dissociation and neuronal labeling procedures, to assess neuronal viability, labeling, and differentiation over the course of the experiments in vivo. $a$, Phase-contrast photomicrograph of a neocortical culture 2 weeks after plating from the transplantation pipette, showing well-differentiated, healthy neurons with good process outgrowth and many intercellular contacts. $b$, Fluorescence appearance of another, less densely populated field of the same culture, showing the range of labeling intensity within neurons from faint cytoplasmic label with few intracellular lysosomal granules (short arrow) to bright cytoplasmic label with many lysosomal granules (long arrow). $c$, Cerebellar culture 2 weeks after plating from the transplantation pipette, showing excellent viability, differentiation, process extension, and intercellular contacts. $d$, Hypoosmotically lysed neocortical cells $1 \mathrm{~d}$ after plating from the transplantation pipette. No viable cells were visible from the time of transplantation; predominantly cellular fragments remained, with a few crenated cells that later disappeared. Scale bar, $60 \mu \mathrm{m}$ for $a-d$.

regions (Fig. $3 A$ ). The reduction in neurons was limited to those with larger cross-sectional areas (Fig. $3 B$ ), with elimination of almost half of medium (70-120 $\left.\mu \mathrm{m}^{2}\right)$ and large (120-220 $\left.\mu \mathrm{m}^{2}\right)$ neurons and almost two-thirds of the larger group alone. The population of small, presumptive local connection neurons was unchanged. Measurements were reproducible between observers, and by the initial observer, for total neuron counts within individual defined $5000 \mu \mathrm{m}^{2}$ tissue areas (yielding neuron densities). Interobserver variability ranged between $\pm 2 \%$ and $\pm 8 \%$, typically $\pm 2-4 \%$, for individual tissue areas, with averages of six areas in a region typically within $\pm 2 \%$ between observers. Repeat cell counts for individual tissue areas varied by $0 \%$ to $\pm 10 \%$ by the initial observer, typically $\pm 0-4 \%$. Neuronal cross- sectional area measurements were similarly reproducible, with repeat measurements varying between $\pm 2 \%$ and $\pm 7 \%$.

Neocortical and cerebellar neurons followed in culture in parallel to the in vivo experiments displayed excellent viability, growth, and differentiation (Fig. $4 a, c$ ). Neurons extended processes and developed dense intercellular contacts by phase-contrast appearance. Labeled neurons retained bright intracellular, granular fluorescence that did not fade during the experiments (Fig. $4 b$ ). Intracellular label varied within a single culture from a few lysosomal granules per neuron to more intense and diffuse label initially, with a trend toward accumulation of label within granules over the first few days. There was also variability of labeling efficiency between different dissociation experiments,

Figure 5. CONTROL, Representative camera lucida drawings of serial sections of mouse brains 1 week to 12 weeks following cell suspension neocortical grafting with E17 cells into control, unlesioned mouse pups. Cellular injections spanned cortical laminae II-V to offer both lateral and laminar choice to labeled neurons. Grafted neurons (individual dots) remained quite localized to the injection track without significant lateral spread or preferential localization (arrows). A single anomalous case at 3 weeks displayed more extensive spread near layer I and corpus callosum, shown in more detail in Figure 6. PHOTOLYTIC DEGENERATION, Neocortical grafts of E17 neurons into P14-P15 mouse pups selectively lesioned by PL at P4-P5. One day after transplantation, neurons remained localized to the injection track, as in controls (small curved arrow). The large curved arrow indicates the geographically defined region of ongoing neuronal degeneration. Two examples are shown at 2 weeks; grafted neurons have preferentially entered and now reside in the selectively neuron-deficient zone in lamina II/III (straight arrows). In deeper laminae, grafted neurons remain localized along the injection track (curved arrows). The upper 2 week case is shown in more detail in Figure 6. KAINIC ACID LESION, Neocortical grafts of E17 neurons into P14-P15 mouse pups with lesions (large arrow) produced by injection of kainic acid at P4-P5. Two weeks after grafting, donor neurons remained localized to the injection track (small arrow); they did not enter the compacted lesion that had been hypocellular at the time of grafting. Scale bars, $1 \mathrm{~mm}$ (scale bar in CONTROL 1 week refers to all panels except PHOTOLYTIC DEGENERATION 1 day, shown at slightly higher magnification). 


\section{CONTROL}

1 week
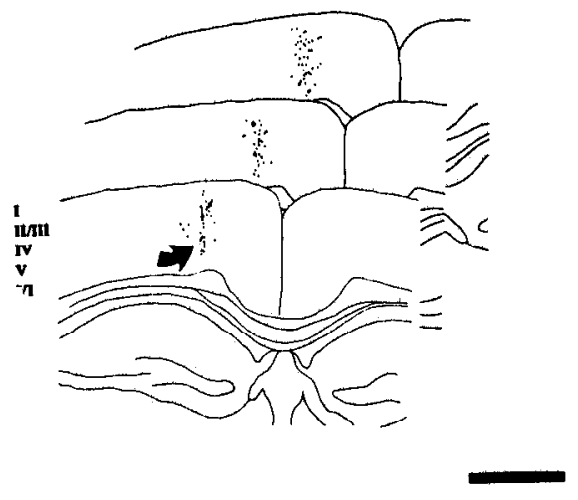

3 weeks

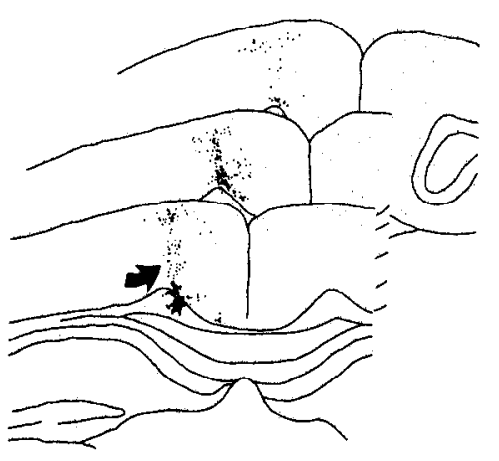

7 weeks

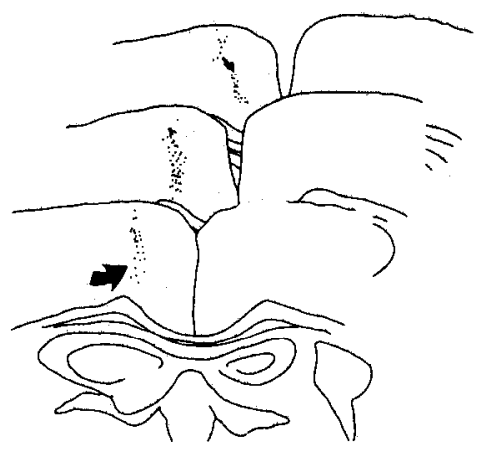

12 weeks

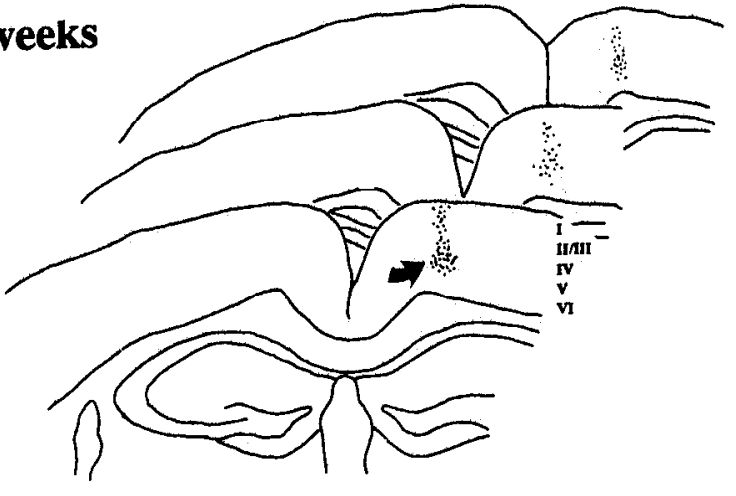

\section{PHOTOLYTIC DEGENERATION}

1 day

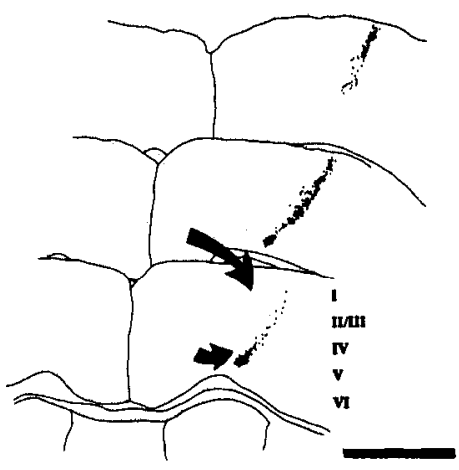

2 weeks
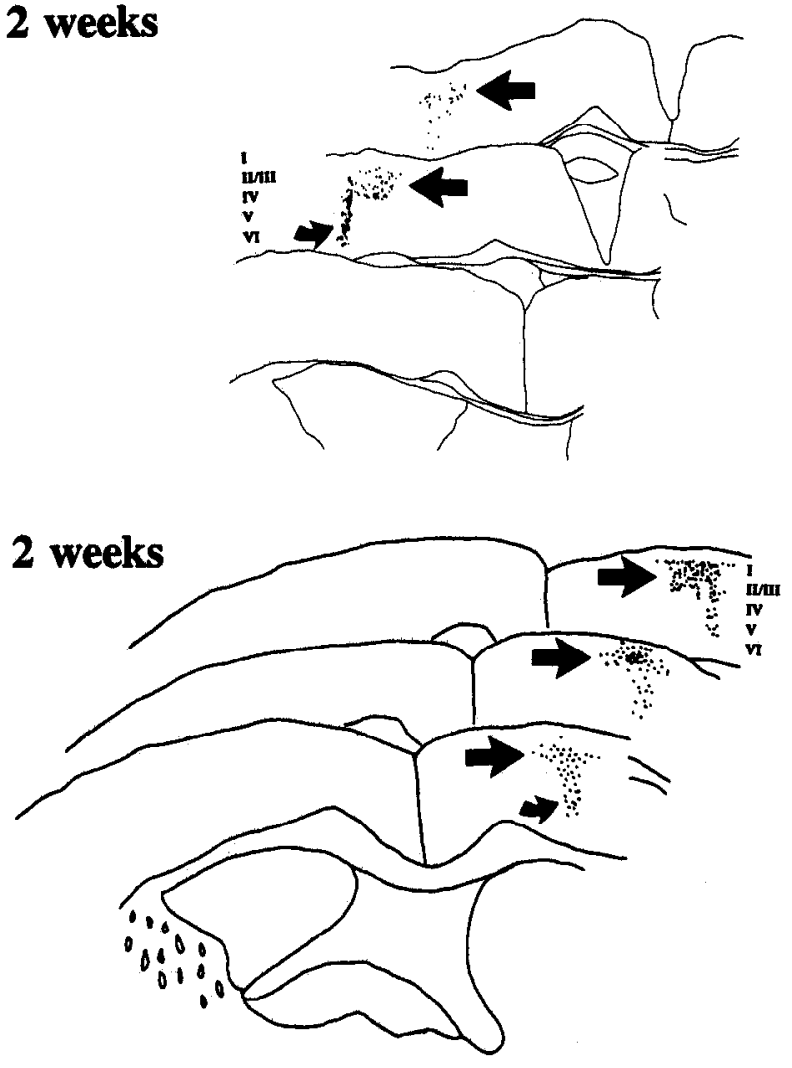

KAINIC ACID LESION

2 weeks

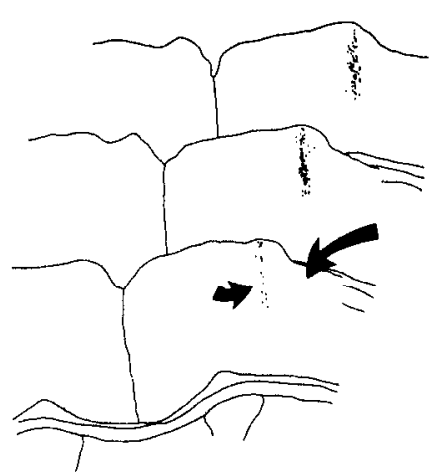




\section{A PHOTOLYTIC DEGENERATION}

Figure 6. Higher-magnification camera lucida drawings of one experimental photolytic degeneration case at 2 weeks and the single anomalous 3 week control case from Figure 5. For each case, regions of interest from three serial sections (every third section; $r$, rostral; $m$, middle; $c$, caudal) are shown along with low-magnification photomicrographs of sections adjacent to section $m$, stained with $\mathrm{CV}$, indicating the cortical laminae $(1-6)$, corpus callosum $(c c)$, and dura (d). A, Migration of $\mathrm{E} 17$ donor neurons 2 weeks after transplantation adjacent to a region of ongoing photolytic degeneration to callosal neurons in lamina II/III (2/3). A subpopulation of donor neurons migrated selectively toward and into this region in a relatively narrow band limited to lamina II/III (arrows). In deeper layers and on the opposite side of the injection track, no significant spread of neurons occurred. $B$, In the single control case with extensive spread of donor neurons, the cellular injection track extended more deeply than desired into the corpus callosum $(c c)$, with significant deposition into the relatively acellular lamina I $(l)$ as well. Dispersed donor neurons appear to cluster predominantly in or near lamina I (arrows) and corpus callosum (arrowheads), although a smaller number of neurons spread within other cortical layers. Scale bar, $250 \mu \mathrm{m}$.

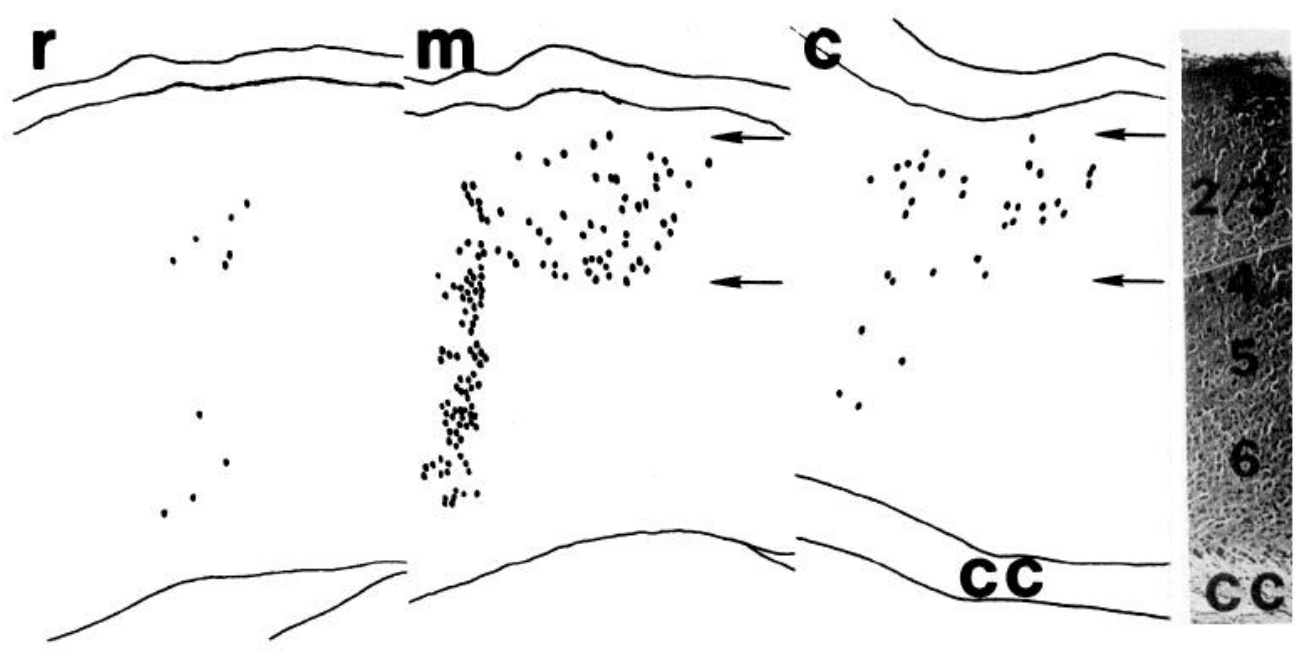

ANOMALOUS CONTROL

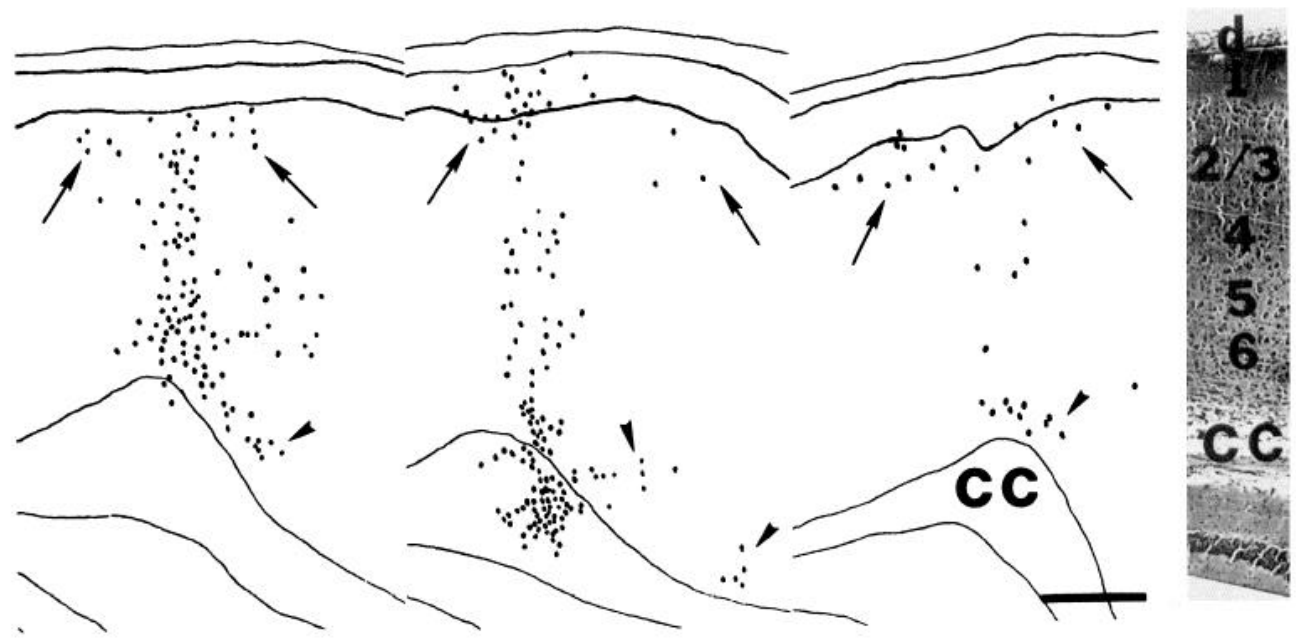

but all contained sufficient label to identify cells well in vivo. Neocortical neurons lysed by hypoosmolar conditions were nonviable, but the aliquots injected into control mice contained numerous nonviable cells and cellular debris (Fig. 4d).

Embryonic neocortical precursor cells from E13-E17 donors transplanted into intact control hosts behaved as expected from the extensive literature of grafts of neocortex, hippocampus, or cerebellum into parenchyma of normal postmigrational or adult hosts. Appropriate dissociation, labeling, and injection methods ensured neuronal viability and morphologic maturation, but transplanted neurons remained extremely localized to their "tubular" shaped injection position spanning cortical layers without preference (Fig. 5). They did not migrate or spread significantly, typically remaining within approximately $100 \mu \mathrm{m}$ of the central injection location. Donor neurons retained a predominantly uninterrupted structural association with other transplanted neurons, readily recognized by bright intracellular label. There was little change in distribution of donor neurons over the wide range of survival times from $1 \mathrm{hr}$ to 12 weeks. Little evidence of gross cellular integration with surrounding parenchyma was seen. Neuronal morphology was typically small and ovoid, and process elongation indicated by intracellular fluorescence was limited. There was no difference in neuronal location or migration with different donor ages from E13 to E17. By 2-3 weeks posttransplantation, control neurons were maximally dispersed, and morphologic differentiation was evident. This guided the timing of analysis of experimental cases at 2 weeks.

In prior pilot studies, aimed primarily at developing reproducible stereotaxic transplant placement within neocortical lamina II-V, more extensive spread was observed when cells were deposited within the white matter of the corpus callosum, or when injections effluxed into layer I of neocortex. When deposited into these relatively acellular layers, transplanted cells formed heterotopias that were clearly delineated from surrounding white matter and parenchyma, but individual neurons did 

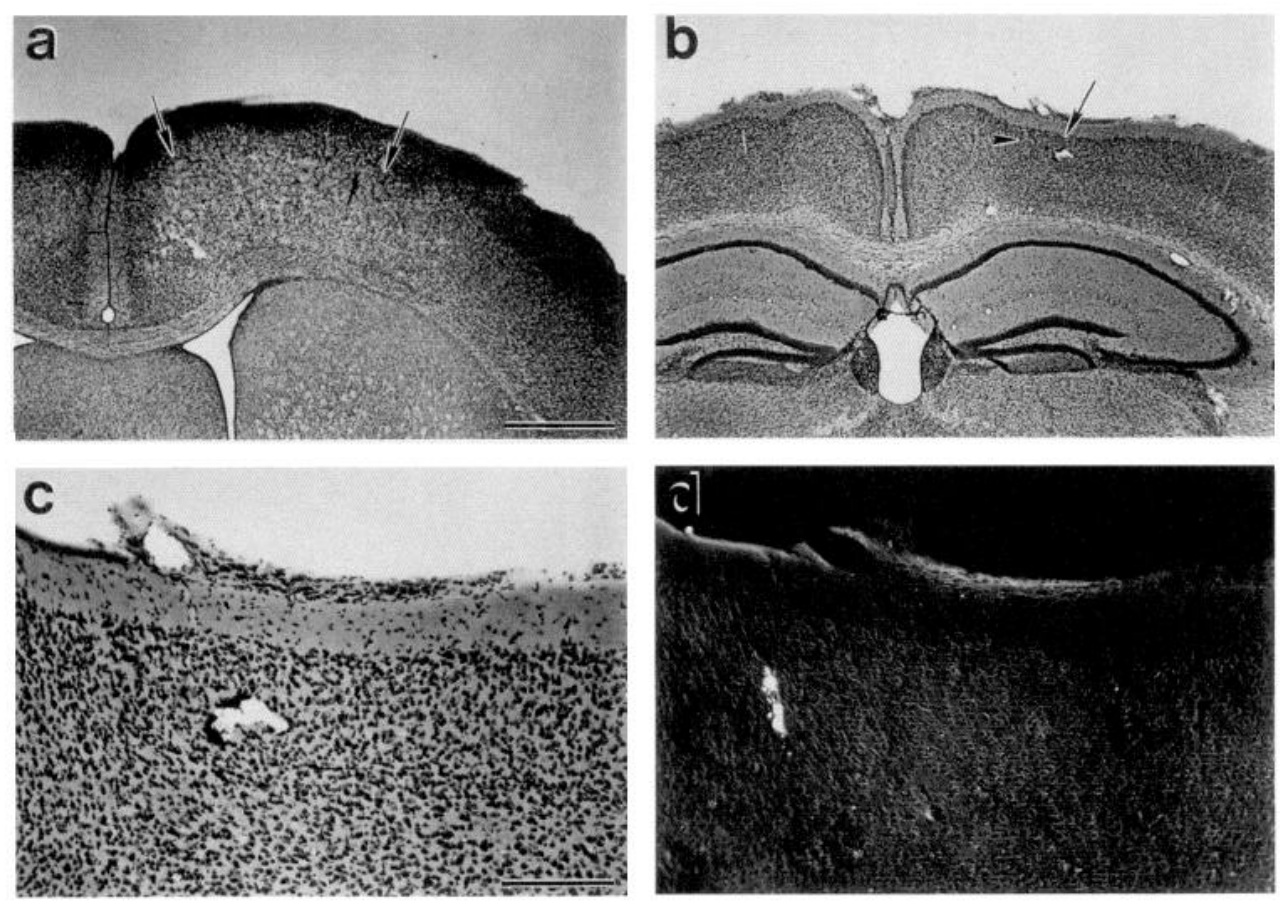

Figure 7. Control neocortical transplantation into mouse pups with lesions to neocortex produced by kainic acid. $a$, At the time of cellular transplantation at P14, 9-10 d after injection of kainic acid at P4-P5, well-demarcated, hypocellular regions of neocortex were clearly visible (arrows). $b$, Two weeks later, these lesioned regions were compacted to a reduced cortical thickness of relatively normal cellular density surrounding the focus of kainic acid injection (arrow). The most superficial portion of the site of cell grafting is indicated by the arrowhead. $c$, Highermagnification view of the region of interest in $b . d$, Combined fluorescence and phase-contrast appearance of this same region of fluorescently labeled grafted neurons within compacted kainic acid lesion. Scale bars: $a$ and $b$, $1 \mathrm{~mm} ; c$ and $d, 250 \mu \mathrm{m}$. not demonstrate gross integration with surrounding tissue. In the prior studies and in the studies reported here, small, morphologically glial cells were seen at relatively large distances from the injection location, typically within white matter tracts, as previously described (Bernstein and Goldberg, 1989). In one anomalous control case (" 3 week" control included as a worst case in Fig. 5), more extensive spread of neurons was observed. Most of this spread was within or near layer I or the corpus callosum (Fig. 6), although a few neurons spread up to $300 \mu \mathrm{m}$ in other cortical layers.

Neocortical neurons transplanted into host neocortex lesioned by kainic acid similarly remained local to the injection position, without significant lateral spread into the extremely pale-staining and hypocellular regions of kainic acid injury (Figs. 5, 7). One hour and $1 \mathrm{~d}$ after transplantation, donor neurons were present as a localized tubular injection in the midst of the hypocellular kainic acid-lesioned zones. Two weeks after transplantation, these tubular neuronal groupings were present within or adjacent to compressed regions of reduced cortical thickness, representing the prior site of widespread neuronal injury induced by kainic acid. There was no significant spread from the injection location.

Cerebellar cells transplanted to lesioned zones of neocortex did not appear viable histologically at $6 \mathrm{~d}$ or 2 weeks, although cultured cells from those same dissociations (and cultured directly from the micropipettes used for transplantation) were extremely healthy and well differentiated for a period of several weeks following transplantation. Tubular groupings of crenated cells and surrounding macrophages were seen. No pyramidal neuron morphology was present.

Hypoosmotically lysed neocortical cells transplanted into intact or lesioned neocortex remained close to the injection site. The regions were surrounded by and infiltrated by "foamy" macrophages within 2-4 d, continuing at 1 and 2 weeks, making the border between the injection zone and surrounding neocortex quite distinct. These cases did not mimic either experimental or control cases in appearance; there was no confounding spread of fluorescent nanospheres to host neurons that would confuse the distinct identification of donor cells. Fluorescence was present either in small, acellular deposits or as diffuse cytoplasmic label within the numerous surrounding phagocytes.

Controls with neocortical transplants at locations isolated from the regions of photolytically induced neuron degeneration revealed localization of donor neurons at the tubular injection location, with only the extremely limited spread seen in the intact host controls. There was no migration across intact neocortex to the regions of photolytic neuron degeneration either 1 week or 2 weeks after transplantation. Morphologically, donor neurons in these animals remained small and ovoid, as in the other control groups.

Embryonic neurons transplanted on E17 into mice with selective, experimentally induced photolytic degeneration of callosally projecting pyramidal neurons in lamina II/III demonstrated strikingly different behavior (Fig. 5). These neurons, placed adjacent to, but not within, the defined zones of neuron deficiency, were offered both a laminar "choice" (the injection spanned layers II-V), and a lateral "choice" within lamina II/ III (neighboring control tissue immediately lateral to the injection site was completely intact). After brief survivals of $1 \mathrm{hr}$ or $1 \mathrm{~d}$, donor neurons remained local to the injection site. Although known from prior silver degeneration studies to be undergoing active degeneration at the time of transplantation, lesioned neurons within these regions were still present. CV histology revealed only subtle pallor in some pyramidal neurons, without gross hypocellularity that theoretically could provide a reduction of physical barriers to movement resulting from pressure injection, potentially allowing nonspecific entry into hypocellular regions at the time of cellular injection. A substantial portion of donor neurons preferentially entered the selectively neuron-deficient zones over the time between $1 \mathrm{~d}$ and 2 weeks posttransplantation, locating up to $700-800 \mu \mathrm{m}$ laterally from the initial site of transplantation, exclusively repopulating the 
A
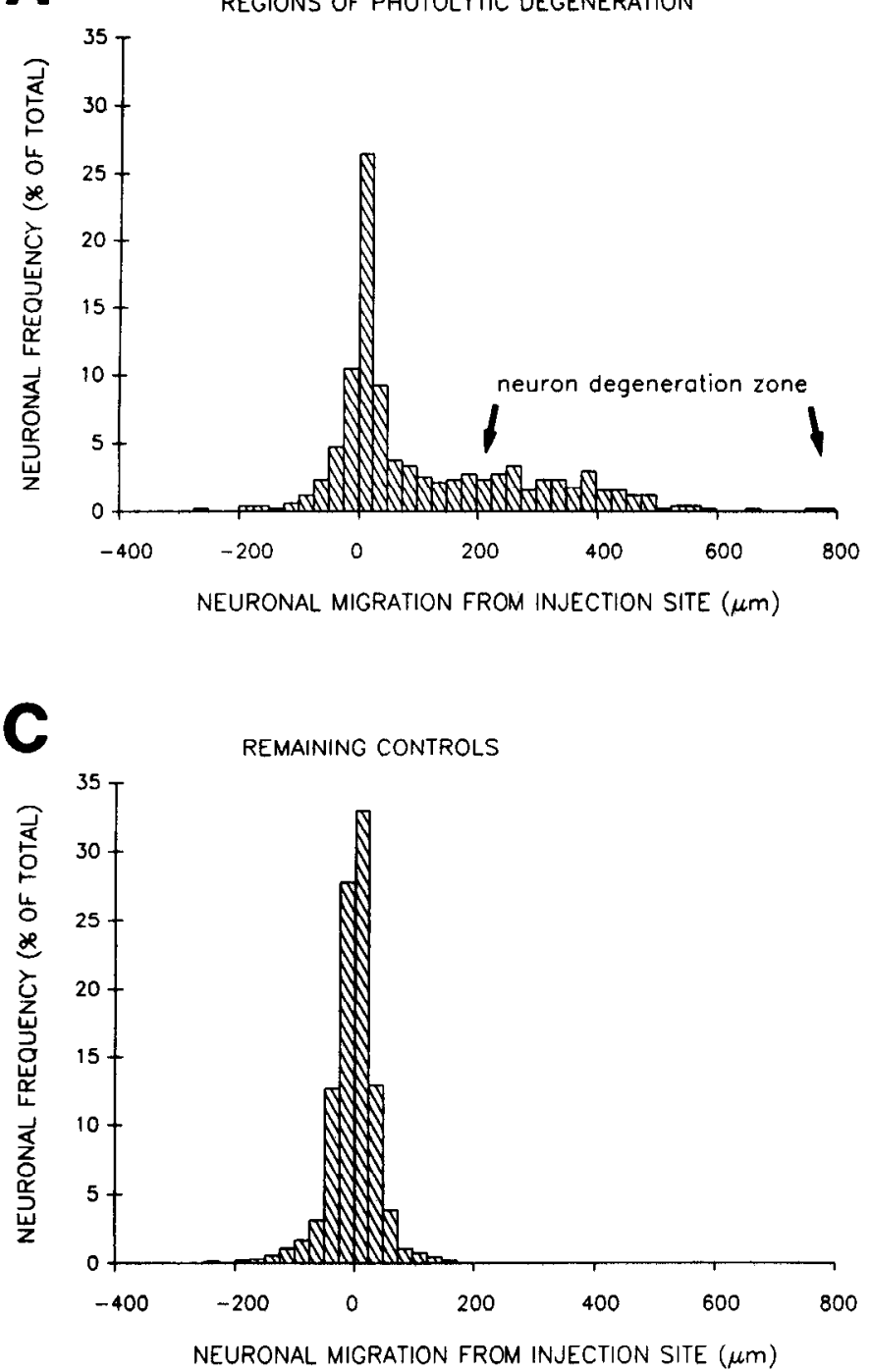

B

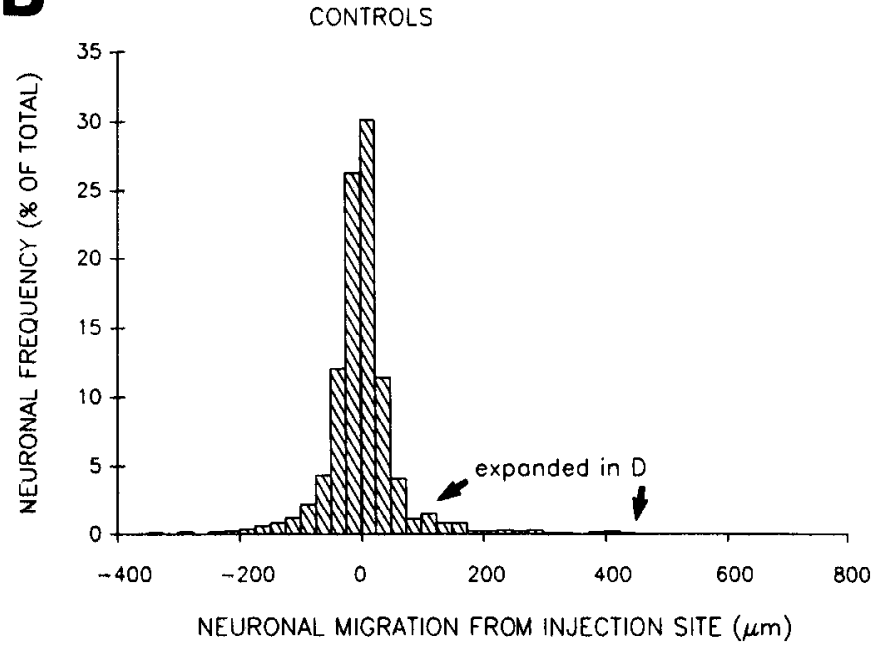

D

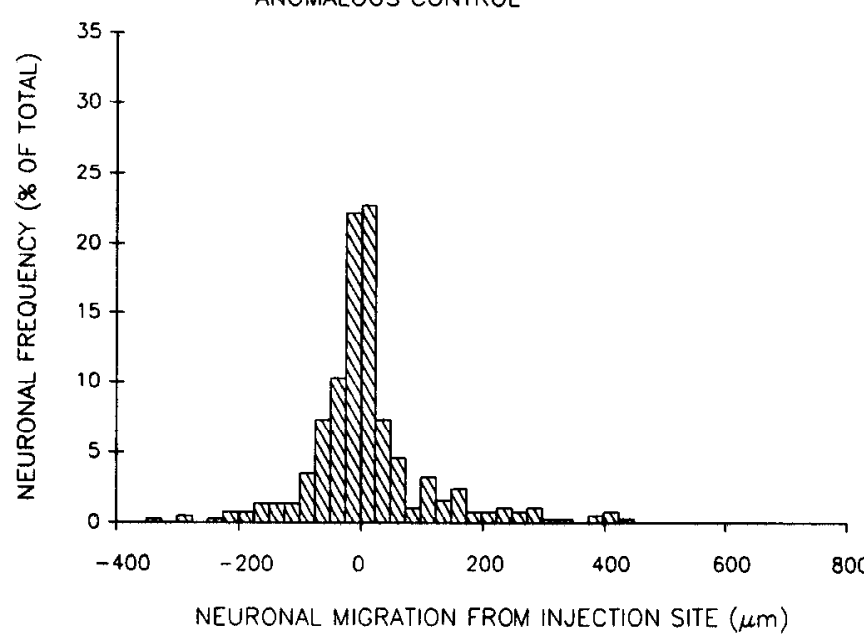

Figure 8. Quantitative analysis of donor neuron positions digitized from camera lucida drawings $(n=18$ from controls, 4056 neurons; $n=6$ from experimentals at 2 weeks, 1521 neurons), showing neuronal migration from the injection sites. $A$, Neurons transplanted adjacent to regions of photolytic degeneration were distributed asymmetrically, with $44 \%$ migrating selectively toward or into the neuron degeneration zones (arrows, typical location), up to $781 \mu \mathrm{m}$. These asymmetrically dispersed neurons may represent the second portion of a bimodal distribution; the remaining $56 \%$ of the neurons were distributed very close to the injection site, similar to controls. $B$, Neurons in controls were distributed relatively closely and symmetrically medial (positive values) and lateral (negative values) to the injection track, with a small percentage of more widely distributed neurons from the single anomalous 3 week control shown in Figure 6 (arrows). $C$, Excluding the single anomalous control, donor neurons in controls were distributed extremely closely and symmetrically. $D$, Neurons in the anomalous control were distributed more widely, but relatively symmetrically, from the injection site.

experimental region. Six of seven cases at 2 weeks displayed qualitatively directed migration to varying degrees into the regions of photolytic degeneration. Neurons did not enter the adjoining control regions of lamina II/III, nor did they spread more in deep layers than in the control cases (Fig. 6). An equivalent proportion of the donor neurons did not migrate; they behaved like those in control mice (small cross-sectional area, ovoid morphology, without integration with host parenchyma).

Quantitative analysis of digitized donor neuron positions confirmed and reinforced these qualitative observations (Fig. 8). Donor neurons in controls including the single anomalous control were distributed relatively symmetrically medial (positive values) and lateral (negative values) to the injection track (Fig. $8 B$ ); mean position was $2 \pm 64 \mu \mathrm{m}$. Excluding the single anom- alous 3 week control removed much of the variance in the control group. Remaining controls had a mean donor neuron position of $-1 \pm 40 \mu \mathrm{m}$ and were distributed extremely symmetrically medial and lateral to the injection track (Fig. $8 C$ ). Donor neurons in experimental cases were widely distributed, very asymmetrically with respect to the injection track (Fig. $8 \mathrm{~A}$; mean position of $110 \pm 165 \mu \mathrm{m})$, with $44 \%(34-54 \%)$ positioned toward or into the region of photolytic degeneration beyond three SDs of the controls (excluding the anomalous control). Only $5.8 \%$ were positioned beyond three SDs on the opposite side of the injection track, with a maximum value of $-251 \mu \mathrm{m}$. The subpopulation of neurons in experimentals beyond three $\mathrm{SD}$ of the controls on the photolytic degeneration side had a mean position of $305 \pm 124 \mu \mathrm{m}$ with a maximum of $781 \mu \mathrm{m}$; 

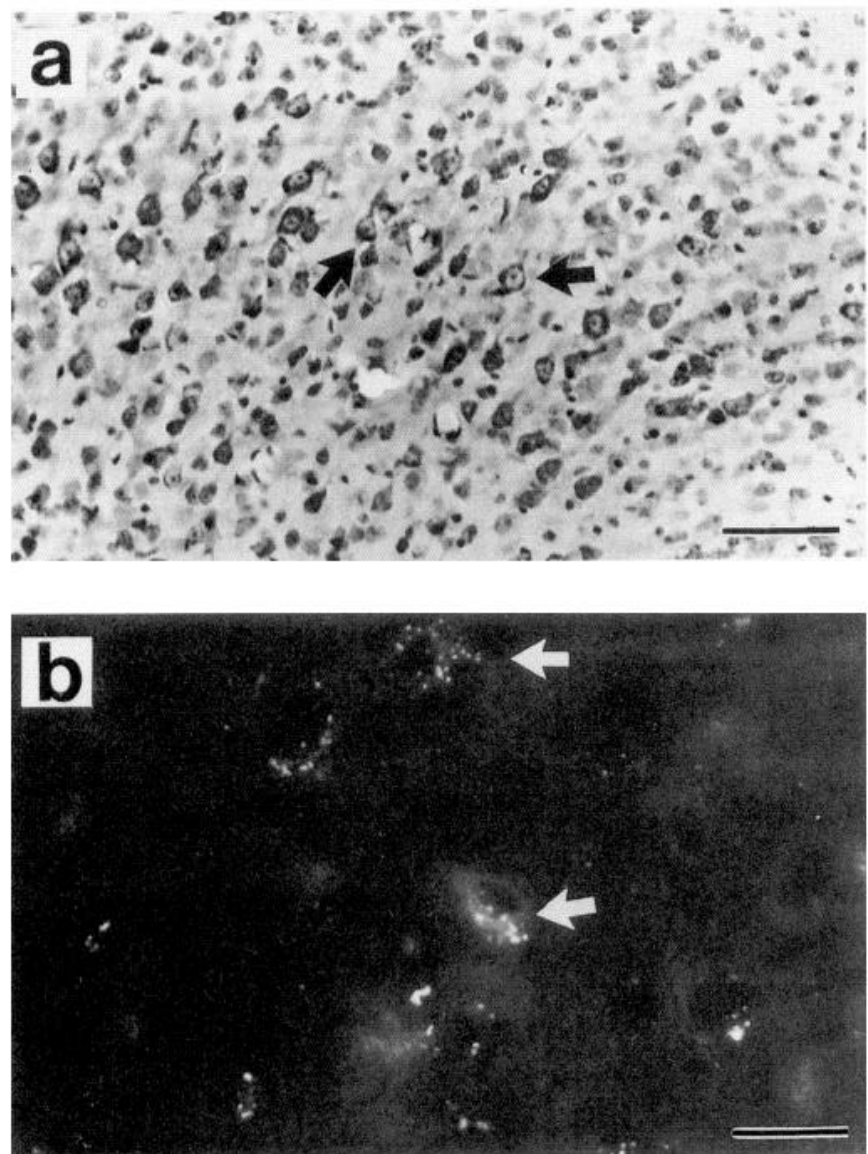

Figure 9. Partially repopulated graft site within neocortex previously selectively lesioned by PL. $a$, CV-stained section showing large-diameter, phenotypically pyramidal neurons laterally dispersed from the injection track (arrows). $b$, Fluorescence image of the same location in the adjacent section showing positive identification of phenotypically pyramidal neurons by distinct intracellular fluorescence (arrows). Scale bars: $a, 50 \mu \mathrm{m} ; b, 20 \mu \mathrm{m}$.

graphically, there is a suggestion that these neurons represent the second portion of a bimodal distribution. The remaining $56 \%$ of the neurons in experimentals had a mean position of 24 $\pm 42 \mu \mathrm{m}$, quite similar to the controls. The relatively wide spread of the neurons in the single anomalous 3 week control case (Fig. $8 D$; mean position of $12 \pm 103 \mu \mathrm{m}$ ) was much more limited and symmetric about the injection track than in the experimentals, without suggestion of a bimodal distribution. The number of neurons positioned beyond three SDs was much more symmetric, $23 \%$ medially and $12 \%$ laterally, with maximum values of 426 and $-330 \mu \mathrm{m}$, respectively.

Morphologically, those neurons within the previously neurondeficient zones assumed large cross-sectional area, pyramidal neuron morphology, very distinct from smaller intrinsic neurons, by both routine histology and intracellular fluorescence (Fig. 9). Although some of the donor neurons within the photolytically lesioned zones were oriented aberrantly, many were histologically appropriate, surrounded by smaller host neurons and occasionally extending both apical dendritic and fine axonal processes. They were uniquely identified at the LM level by both their distinct morphologic appearance as clusters of pyramids within surrounding regions otherwise lacking such neurons and by their granular labeling with the nanospheres marking donor neurons.
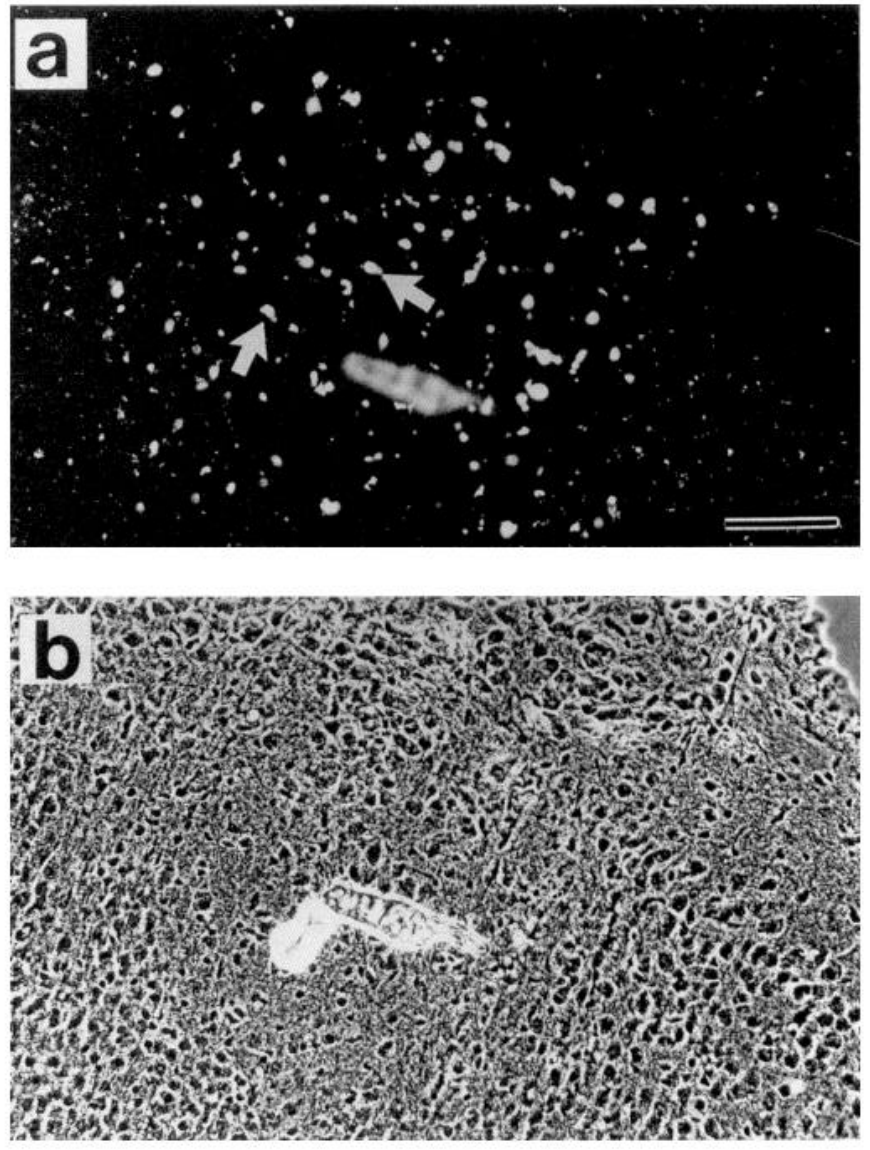

Figure 10. a, I hick section allowing microdissection tor EM analysis of identified neurons: fluorescence appearance of grafted neurons (arrows) within the previously selectively neuron-deficient zone in lamina II/III. $b$, Phase-contrast appearance of the same field, showing partial repopulation with large diameter pyramidal neurons. Scale bar, $100 \mu \mathrm{m}$.

Further assurance that the neurons identified by fluorescence within these zones were donor in origin was provided by EM analysis of the thick sections that were microdissected after fluorescence and phase-contrast examination to include labeled neurons (Fig. 10; Quattrochi et al., 1987). The intact thick sections were used only to confirm the overall distribution of labeled cells seen in other, thinner sections; they were not used to differentiate neurons from non-neuronal cells, or to analyze the morphologic phenotype of labeled neurons. Low-magnification EM analysis $(5000-10,000 \times)$ allowed rapid, distinct identification of donor neurons (Fig. 11), using standard morphologic criteria including pale nuclei that are large relative to the cytoplasm, dispersed nuclear chromatin, prominent nucleoli, abundant rough endoplasmic reticulum and ribosomes, numerous mitochondria, prominent Golgi complex, lysosomes, microtubules, and occasional axosomatic synapses (Jones, 1983; Peters et al., 1991). Lysosomal vesicles approximately 400-500 $\mathrm{nm}$ in diameter were easily recognized within donor neurons by the extremely electron-dense nanospheres, approximately $30-70 \mathrm{~nm}$ in diameter, contained within them. The combination of neuronal morphology, unique fluorescence, nanosphere inclusion within lysosomes, and colloidal gold label provided a high level of certainty regarding the donor origin of these neurons. The control transplants of hypoosmotically lysed neocortical cells further argue against potential confusion by passive transfer of nanospheres to host neurons; phagocytes accumu- 
Figure 11. A, Electron micrograph showing the ability to identify rapidly at low-magnification $(10,000 \times)$ grafted neurons that contain uniquely electrondense nanospheres within lysosomal granules (arrows). B, Higher-magnification $(100,000 \times)$ view showing a typical lysosomal granule (open arrow) containing several nanospheres (straight solid arrow) coated with colloidal gold (curved arrow). Scale bars: $A, 500 \mathrm{~nm}$; $B, 50 \mathrm{~nm}$
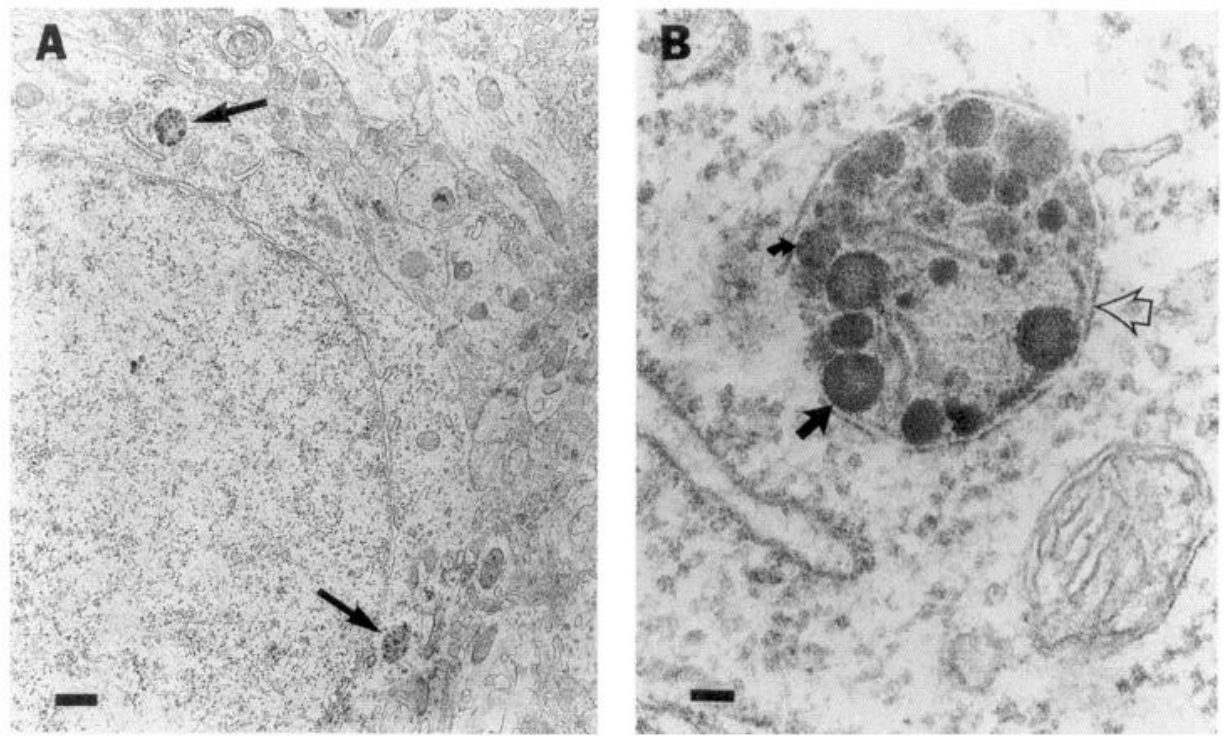

lated these released nanospheres local to the injection location, and no labeled neurons were seen distant from the injection (where EM analysis was performed). Other indirect evidence further supports this and argues against the possibility that identified neurons could be host neurons that accumulated free nanospheres following the transplant injection or after lysis of some donor cells: (1) these labeled cells were located distant to the tubular transplantation site only within the lesioned zones, not in the symmetrically located area of lamina II/III, and not in other layers as one might expect if host labeling occurred; (2) labeled neurons in other layers in the experimental mice and neurons in all layers in control mice displayed nonpyramidal phenotype, a specificity not consistent with host uptake of free nanospheres; (3) the intensity of donor neuron labeling was qualitatively distinct from labeling observed after direct injection of nanospheres into neocortex (direct application in vitro during the dissociation of embryonic neurons yields a much more intense labeling than with differentiated neurons in situ).

\section{Discussion}

The results presented in this report suggest that transplanted neocortical neurons will migrate to restore normal cytoarchitecture if provided with an appropriately permissive host environment. There may be multiple levels of hierarchical control over the migration and laminar positioning of neocortical neurons during development and, therefore, during attempts to experimentally repopulate regions of neocortex. During the normal developmental timetable in cortex, a specific time sequence of expression of neuronal, glial, trophic, and adhesive signals may occur, and these naturally disappear after a relatively brief period. Some of these permissive or enhancing factors may be upregulated or reactivated given a specific enough degeneration of a selected subpopulation of neurons. The host model used in these studies was designed to provide control and definition over both temporal rate and extent of the neuronal dropout, and, therefore, these possible host environmental cues.

We chose E17 donor neurons for initial study for several reasons. Neurons of this age are known to dissociate and grow well in culture, thus allowing the necessary prelabeling and parallel culture observation. The generation and migration of neo- cortical neurons is most active between E14/15 and E17/18 in mice (Angevine and Sidman, 1961; Austin and Cepko, 1990). At E17, most newly postmitotic neurons leaving the germinal matrix and entering the migrational phase within neocortex are destined to form the superficial lamina, notably lamina II/III made most profoundly neuron deficient by these selective photolytic lesions. This age of donor population, therefore, provides a sample at the height of neuronal migration; future experimental variation of embryonic donor age to both earlier and later times (E14 and E19, e.g.) is possible.

The striking finding of apparent preferential migration of a subpopulation of transplanted E17 neurons (presumably the portion still in migrational phase) to the selectively neurondeficient zone in young postnatal hosts may provide a partial answer to the hypothesis under study regarding restoration of normal cytoarchitectonics. The suggestion from these first experiments is that, even after the normal period for appropriate neuronal migration to correct laminar positions is completed, it is possible to reactivate a specific combination of environmental cues to allow neuronal migration that otherwise would not occur in normal or nonspecifically lesioned animals. It is possible that such reactivated cues are capable of at least partially superseding intrinsic neuronal signals acquired during the cell cycle within the germinal matrix (McConnell and Kaznowski, 1991), allowing repopulation by neocortical neurons otherwise "destined" to form other, deeper laminae, for example, or by appropriately pluripotent neural cell lines. Important contributions may be provided by extracellular matrix components, glial populations via reexpression of radial glial morphology (Geschwind and Hockfield, 1989; Culican et al., 1990; Rosen et al., 1990), and neuronal populations of localcircuit neurons and more distant afferents.

Two lines of inquiry suggest that integration in "point-topoint" systems is possible if host and donor conditions are appropriate; definition of these complex conditions and necessary modifications are not established. Studies using the cerebellum of PCD mutant mice by Sotelo, Alvarado-Mallart, and colleagues have shown the feasibility of neural grafting procedures to restore damaged neuronal systems that are connected in a "point-to-point" fashion (Sotelo and Alvarado-Mallart, 
1986, 1987a,b; Gardette et al., 1990; Sotelo et al., 1990). Embryonic transplants of cerebellum partially repopulate the defective host cerebellum with Purkinje cells and establish relatively appropriate, specific afferent synaptic contacts. Grafted Purkinje cells appear to retain their own "internal clock" of the normal developmental and migrational sequence and timetable. Based on these studies, it is possible that migration and integration of embryonic or genetically engineered neurons transplanted into appropriately diseased neocortex will mimic events occurring during normal ontogeny. However, McConnell and colleagues have defined the importance of the normal developing host environment to laminar specification, suggesting limitations on such migrational potential by immature neocortical neurons when grafted heterochronically within normal, unlesioned neocortex of the still-developing postnatal ferret (McConnell, 1985, 1988b; McConnell and Kaznowski, 1991). In these studies, early transplants placed prior to mitosis into older but still actively developing hosts migrated and integrated within appropriate host-specified lamina. Transplants that lacked this early environmental "priming" either migrated to their donor-specified locations or failed to migrate at all. These neurons did not integrate within locations destined for population by neurons generated within the host on the day of transplantation, suggesting limited potential to alter laminar "fate" after a brief developmental period. These results and those with PCD mice are not entirely inconsistent within an interpretation that the host "milieu" can be permissive to immature migrational phase neurons, but that exquisitely selective models of neuronal degeneration are necessary to allow appropriate cellular laminar positioning, cellular integration, and intercellular connections. Two alternative interpretations of the findings are that (1) the uniqueness of cerebellar Purkinje cell specification offers more redirected growth to restore appropriate positioning whereas increased inherent complexity in neocortex makes appropriate migration difficult, or (2) the PCD neuronal degeneration produces necessary cues that are absent in the intact developing ferret neocortical system.

A general disadvantage of using neurologically mutant mice for such studies in neocortex is that mutations are random in their occurrence and frequently unclear as to their origin; it is often unknown whether the observed defects are primary or lower-order effects of the mutations (Heckroth et al., 1989; Messer et al., 1991). Most importantly, cerebral cortex is a region for which no mutant model of selective cell loss exists. The host model used in these studies allows lesions to preselected neuronal populations in vivo; it is flexible and avoids such disadvantages. The rate, cell type, and geographic localization for neuronal damage can be precisely controlled, leaving contiguous control regions.

The goal of the experiments described in this report was to investigate whether transplanted embryonic neurons within a host environment beyond the normal migrational period can be "convinced" by reemergence of appropriate neuronal or glial surface cues, inducible factor gradients, or newly available, appropriate neuronal "addresses" to migrate into positions lacking neurons that are normally generated and integrated much earlier within a normal, developing mouse. Specific repopulation after normal ontogeny is complete indicates environmental cues that can be reactivated in more mature rodents to initiate or permit reconstitution of normal cytoarchitecture (Bronner-Fraser, 1987; Adler and Hatlee, 1989; Geschwind and Hockfield, 1989; Miyatani et al., 1989; Savio and Schwab, 1989; Bolz et al., 1990;
Cattaneo and McKay, 1990; Cohen et al., 1991; Lu et al., 1991). Just as the Purkinje cell layer deficient in neurons in the PCD mutant is selectively repopulated after transplantation of immature cerebellum, the lamina of host neocortex deficient in neurons in these photolytically lesioned mice may exert selective neurotropic action on embryonic neocortical neurons. Further experiments will allow us to test the hypothesis more completely, making specific variations in donor age, host age, extent of neuronal depletion, time after initiation of neuronal degeneration, or type of modified donor cells, probing specific aspects of the host environment and donor response. Experiments can apply autoradiographic "birthdate" analysis to identify potential differences between donor neurons that migrate and those that do not. Anatomic investigation of ultrastructural integration, synaptogenesis, and potentially appropriate or inappropriate projections by these transplanted neurons will indicate the extent to which host environmental signals are able to control donor neuron development in vivo. Similarly, such cues may allow earlier pluripotent progenitor cells or immortalized cell lines to differentiate and acquire correct neuronal phenotypes when transplanted into host environments providing appropriate and specific developmental signals.

\section{References}

Adler R, Hatlee M (1989) Plasticity and differentiation of embryonic retinal cells after terminal mitosis. Science 243:391-393.

Anderson KJ, Dam D, Lee S, Cotman CW (1988) Basic fibroblast growth factor prevents death of lesioned cholinergic neurons in vivo. Nature 332:360-362.

Anderson RR, Parrish JA (1983) Selective photothermolysis: precise microsurgery by selective absorption of pulsed radiation. Science 220: $524-527$

Angevine JB Jr, Sidman RL (1961) Autoradiographic study of the cell migration during histogenesis of cerebral cortex in the mouse. Nature 192:766-768.

Arendt T, Allen Y, Sinden J, Schugens MM, Marchbanks RM, Lantos PL, Gray JA (1988) Cholinergic-rich brain transplants reverse alcohol-induced memory deficits. Nature 332:448-450.

Austin CP, Cepko CL (1990) Cellular migration patterns in the developing mouse cerebral cortex. Development 110:713-732.

Bently D, Caudy M (1983) Pioneer axons lose directed growth after selective killing of guidepost cells. Nature 304:62-65.

Bernstein JJ, Goldberg WJ (1989) Graft derived reafferentation of host spinal cord is not necessary for amelioration of lesion-induced deficits: possible role of migrating grafted astrocytes. Brain Res Bull 22:139-146.

Bickford-Wimer P, Granholm A-C, Bygdeman M, Hoffer B, Olson L, Seiger A, Stromberg I (1987) Human fetal cerebellar and cortical tissue transplanted to the anterior eye chamber of athymic rats: electrophysiological and structural studies. Proc Natl Acad Sci USA 84: 5957-5961.

Bjorklund A, Stenevi U, Dunnett SB, Gage FH (1982) Cross-species neural grafting in a rat model of Parkinson's disease. Nature 298: $652-654$.

Bolz J, Novak N, Gotz M, Bonhoeffer T (1990) Formation of targetspecific neuronal projections in organotypic slice cultures from rat visual cortex. Nature 346:359-362.

Bronner-Fraser M (1987) Perturbation of cranial neural crest migration by the HNK-1 antibody. Dev Biol 123:321-331.

Buszaki G, Ponomareff G, Bayardo F, Shaw T, Gage FH (1988) Suppression and induction of epileptic activity by neuronal grafts. Proc Natl Acad Sci USA 85:9327-9330.

Cattaneo E, McKay R (1990) Proliferation and differentiation of neuronal stem cells regulated by nerve growth factor. Nature 347:762765.

Cohen CS, Dreyfus CF, Black IB (1991) NGF and excitatory neurotransmitters regulate survival and morphogenesis of cultured cerebellar Purkinje cells. J Neurosci 11:462-471.

Culican SM, Baumrind NL, Yamamoto M, Pearlman AL (1990) Cor- 
tical radial glia: identification in tissue culture and evidence for their transformation to astrocytes. J Neurosci 10:684-692.

Dang LC (1990) Photochemical photolysis: an approach to non-invasive, selective lesioning of pain sensitive neurons in mouse dorsal root ganglia. Biophysics B.A. thesis, Harvard University.

Dawson TM, Dawson VL, Gage FH, Fisher LJ, Hunt MA, Wamsley JK (1991) Functional recovery of supersensitive dopamine receptors after intrastriatal grafts of fetal substantia nigra. Exp Neurol 111:282292.

Dichter MA (1978) Physiological identification of GABA as the inhibitory transmitter for mammalian cortical neurons in cell culture. Brain Res 149:279-293.

Dunnett SB, Rogers DC, Richards SJ (1989) Nigrostriatal reconstruction after 6-OHDA lesions in rats: combination of dopamine-rich nigral grafts and nigrostriatal "bridge" grafts. Exp Brain Res 75:523535.

Eclancher F, Ramirez JJ, Stein DG (1985) Neonatal brain damage and recovery: intraventricular injection of NGF at time of injury alters performance of active avoidance. Dev Brain Res 19:227-235.

Eisen JS, Pike SH, Debu B (1989) The growth cones of identified motor neurons in embryonic zebrafish select appropriate pathways in the absence of specific cellular interactions. Neuron 2:1097-1 104.

Ettensohn CA (1990) Cell interactions in the sea urchin embryo studied by fluorescence photoablation. Science 248:1115-1118.

Fisher LJ, Jinnah HA, Kale LC, Higgins GA, Gage FH (1991) Survival and function of intrastriatally grafted primary fibroblasts genetically modified to produce L-dopa. Neuron 6:371-380.

Fredericksen K, Jat PS, Valtz N, Levy D, McKay R (1988) Immortalization of precursor cells from the mammalian CNS. Neuron 1:439448.

Freed WJ (1983) Functional brain tissue transplantation: reversal of lesion-induced rotation by intraventricular substantia nigra and adrenal medulla grafts, with a note on intracranial retinal grafts. Biol Psychiatry 18:1205-1267.

Gage FH, Fisher LJ (1991) Intracerebral grafting: a tool for the neurobiologist. Neuron $6: 1-12$.

Gage FH, Dunnett SB, Stenevi U, Bjorklund A (1983) Aged rats: recovery of motor impairments by intrastriatal nigral grafts. Science 221:966-968.

Gage FH, Bjorklund A, Stenevi U, Dunnett SB, Kelly PAT (1984) Intrahippocampal septal grafts ameliorate learning impairments in aged rats. Science 225:533-536.

Gage FH, Wolff JA, Rosenberg MB, Xu L, Yee J-K, Shults C, Friedmann T (1987) Grafting genetically modified cells to the brain: possibilities for the future. Neuroscience 23:795-807.

Gardette R, Crepel F, Alvarado-Mallart RM, Sotelo C (1990) Fate of grafted embryonic Purkinje cells in the cerebellum of the adult "Purkinje cell degeneration" mutant mouse. II. Development of synaptic responses: an in vitro study. J Comp Neurol 295:188-196.

Geschwind DH, Hockfield S (1989) Identification of proteins that are developmentally regulated during early cerebral corticogenesis in the rat. J Neurosci 9:4303-4317

Gibbs RB, Cotman CW (1987) Factors affecting survival and outgrowth from transplants of entorhinal cortex. Neuroscience 21:699706.

Gibbs RB, Harris EW, Cotman CW (1985) Replacement of damaged cortical projections by homotypic transplants of entorhinal cortex. $\mathrm{J}$ Comp Neurol 237:47-64.

Goetz CG, Olanow CW, Koller WC, Penn RD, Cahill D, Morantz R, Stebbins G, Tanner CM, Klawans HL, Shannon KM, Comella CL, Witt T, Cox C, Waxman M, Gauger L (1989) Multicenter study of autologous adrenal medullary transplantation to the corpus striatum in patients with advanced Parkinson's disease. New Engl J Med 320: 337-341.

Gonzalez MF, Sharp FR (1987) Fetal frontal cortex transplanted to injured motor/sensory cortex of adult rats. I. NADPH-diaphorase neurons. J Neurosci 7:2991-3001.

Heckroth JA, Goldwitz D, Eisenman LM (1989) Purkinje cell reduction in the reeler mutant mouse: a quantitative immunohistochemical study. J Comp Neurol 279:546-555.

Hibbard E, Erlich D (1982) Laser-induced defects of retinal development in chick embryos. Neurosci Lett 34:221-226.

Hohmann CF, Ebner FF (1988) Basal forebrain lesions facilitate adult host fiber ingrowth into neocortical transplants. Brain Res 448:5366.
Horellou P, Brundin P, Kalen P, Mallet J, Bjorklund A (1990) In vivo release of dopa and dopamine from genetically engineered cells grafted to the denervated rat striatum. Neuron 5:393-402.

Horn KM, Carey RG (1987) Kainic acid-induced terminal degeneration in the dorsal lateral geniculate of tree shrew. Brain Res 416: 187-191.

Houle JD, Reier PJ (1989) Regrowth of calcitonin gene-related peptide (CGRP) immunoreactive axons from the chronically injured rat spinal cord into fetal spinal cord tissue transplants. Neurosci Lett 103:253258.

Hugon J, Vallat JM, Spencer PS, Leboutet MJ, Barthe D (1989) Kainic acid induces early and delayed degenerative neuronal changes in rat spinal cord. Neurosci Lett 104:258-262.

Isacson O, Dunnett SB, Bjorklund A (1986) Graft-induced behavioral recovery in an animal model of Huntington disease. Proc Natl Acad Sci USA 83:2728-2732.

Jaeger CB, Lund RD (1980) Transplantation of embryonic occipital cortex to the brain of newborn rats. Exp Brain Res 40:265-272.

Jay DG, Keshishian H (1990) Laser inactivation of fasciclin I disrupts axon adhesion of grasshopper pioneer neurons. Nature 348:548-550.

Jones EG (1983) The structural basis of neurobiology. New York: Elsevier.

Juliano SL, Dusart I, Peschanski M (1989) Somatic activation of thalamic neurons transplanted into lesioned somatosensory thalamus. Brain Res 478:356-360.

Kater SB, Hadley RD (1982) Video monitoring of neuronal plasticity. Trends Neurosci 5:80-82.

Katz LC, Burkhalter A, Dreyer WJ (1984) Fluorescent latex microspheres as a retrograde neuronal marker for in vivo and in vitro studies of visual cortex. Nature 310:498-500.

Kesslak JP, Nieto-Sampedro M, Globus J, Cotman CW (1986) Transplants of purified astrocytes promote behavioral recovery after frontal cortex ablation. Exp Neurol 92:377-390.

Klassen H, Lund RL (1990) Retinal graft-mediated pupillary responses in rats: restoration of a reflex function in the mature mammalian brain. J Neurosci 10:578-587.

Kromer LF (1987) Nerve growth factor treatment after brain injury prevents neuronal death. Science 235:214-216.

Kromer LF, Bjorklund A, Stenevi U (1983) Intracephalic embryonic neural implants in the adult rat brain. I. Growth in mature organization of brainstem, cerebellar, and hippocampal implants. J Comp Neurol 218:433-459.

Labbe R, Firl A, Mufson EJ, Stein DG (1983) Fetal brain transplants: reduction of cognitive deficits in rats with frontal cortex lesions. Science 221:470-472.

Lee HJ, Hoffmann PC, Kontur PJ, Won LA, Hammond DN, Wainer BH (1991) Immortalization of mesencephalic dopaminergic neurons by somatic cell fusion. Brain Res 552:67.

Lindsay KM, Kaisman G, Seeley PJ (1987) Intracerebral transplantation of cultured neurons after reaggregation in a plasma clot. Neuroscience 21:685-698.

Lindvall O, Brundin P, Widner H, Rehncrona S, Gustavii B, Frackowiak R, Leenders KL, Sawle G, Rothwell JC, Marsden CD, Bjorklund A (1990) Grafts of fetal dopamine neurons survive and improve motor function in Parkinson's disease. Science 247:574-577.

Liu FC, Graybiel AM, Dunnett SB, Baughman RW (1990) Intrastriatal grafts derived from fetal striatal primordia. II. Reconstitution of cholinergic and dopaminergic systems. J Comp Neurol 295:1-14.

Lu B, Yokoyama M, Dreyfus CF, Black IB (1991) NGF gene expression in actively growing brain glia. J Neurosci 11:310-326.

Macklis JD (1991) Migration of transplanted embryonic neocortical neurons into selectively neuron-deficient cortex of early postnatal mice. Soc Neurosci Abstr 17:50.

Macklis JD, Madison R (1985) Unfocused laser illumination kills dyetargeted mouse neurons by selective photothermolysis. Brain Res 359: $158-165$.

Macklis JD, Madison RD (1991) Neuroblastoma grafts are noninvasively removed within mouse neocortex by selective laser activation of intracellular photolytic chromophore. J Neurosci 11:20552062.

Macklis JD, Quattrochi JJ (1991) Restricted diffusion and stability of carbachol-fluorescent nanospheres in vivo. Neuroreport 2:247-250.

Madison R, Macklis JD (1989a) Noninvasive laser lesioning of neuronal subpopulations. In: Selective lesioning in the nervous system, pp 42-52. Washington, DC: Society for Neuroscience. 
Madison R, Macklis JD (1989b) Noninvasive laser lesioning of mouse neocortical neurons in vivo. Soc Neurosci Abstr 15:9.

Madison RD, Macklis JD (1993) Noninvasively induced degeneration of neocortical pyramidal neurons in vivo: selective targeting by laser activation of retrogradely transported photolytic chromophore. Exp Neurol, in press.

Madison RD, Macklis JD, Frosch MP (1988) Noninvasive laser microsurgery selectively damages labeled mouse neurons: dependence on incident laser dose and absorption. Brain Res 445:101-110.

Madison R, Macklis J, Thies C (1990) Latex nanosphere delivery system (LNDS): novel nanometer-sized carriers of fluorescent dyes and active agents selectively target neuronal subpopulations via uptake and retrograde transport. Brain Res 522:90-98.

McConnell SK (1985) Migration of cerebral cortical neurons after transplantation into the brains of ferrets. Science 229:1268-1271.

McConnell SK (1988) Fates of visual cortical neurons in the ferret after isochronic and heterochronic transplantation. J Neurosci 8:945974.

McConnell SK, Kaznowski CE (1991) Cell cycle dependence of laminar determination in developing neocortex. Science 254:282-285.

Messer A, Eisenberg B, Plummer JJ (1991) The Lurcher cerebellar mutant phenotype is not expressed on a staggerer mutant background. J Neurosci 11:2295-2302.

Miller JP, Selverston AI (1979) Rapid killing of single neurons by irradiation of intracellularly injected dye. Science 206:702-704.

Miyatani S, Shimamura K, Hatta M, Nagafuchi A, Nose A, Matsunaga M, Hatta K, Takeichi M (1989) Neural cadherin: role in selective cell-cell adhesion. Science 245:631-635.

Nietro-Sampedro M, Whittemore SR, Needels DL, Larson J, Cotman CW (1984) The survival of brain transplants is enhanced by extracts from injured brain. Proc Natl Acad Sci USA 81:6250-6254.

Nilsson OG, Kalen P, Rosengren E, Bjorklund A (1990) Acetylcholine release from intrahippocampal septal grafts is under control of the host brain. Proc Natl Acad Sci USA 87:2647-2651.

Norman AB, Thomas SR, Pratt RG, Samaratunga RC, Sanberg PR (1989) Magnetic resonance imaging of rat brain following kainic acidinduced lesions and fetal striatal tissue transplants. Brain Res 483: 188-191.

Otto D, Unsicker K (1990) Basic FGF reverses chemical and morphological deficits in the nigrastriatal system of MPTP-treated mice. J Neurosci 10:1912-1921.

Peschanki M, Besson JM (1987) Structural alteration and possible growth of afferents after kainate lesion in adult rat thalamus. J Comp Neurol 258:185-182.

Peters A, Palay SL, Webster HD (1991) The fine structure of the nervous system, neurons, and their supporting cells, $3 \mathrm{~d}$ ed. Oxford: Oxford UP.

Quattrochi J, Madison R, Sidman RL, Kljavin I (1987) Colloidal gold fluorescent microspheres: a new retrograde marker visualized by light and electron microscopy. Exp Neurol 96:219-224.

Quattrochi JJ, Mamelak AN, Madison RD, Macklis JD, Hobson JA (1989) Mapping neuronal imputs to REM sleep induction sites with carbachol-fluorescent microspheres. Science 245:984-986.

Ralph MR, Foster RG, Davis FC, Menaker M (1990) Transplanted suprachiasmatic nucleus determines circadian period. Science 247: 975-978.

Raper JA, Bastiani MJ, Goodman CS (1984) Pathfinding by neuronal growthcones in grasshopper embryos. IV. The effects of ablating the $A$ and $P$ axons upon the behavior of the $G$ growthcone. $J$ Neurosci 4:2329-2345.

Redmond DE, Naftolin F, Collier TJ, Leranth C, Robbins RJ, Sladek CD, Roth RH, Sladek JR (1988) Cryopreservation, culture, and transplantation of human fetal mesencephalic tissue into monkeys. Science 242:768-771.

Renfranz PJ, Cunningham MG, McKay RDG (1991) Region-specific differentiation of the hippocampal stem cell line HiB5 upon implantation into the developing mammalian brain. Cell 66:713-729.
Ronnett GV, Hester LD, Nye IS, Connors K, Snyder SH (1990) Human cortical neuronal cell line: establishment from a patient with unilateral megalencephaly. Science 248:603-605.

Rosen GD, Press DM, Sherman GF, Galaburda AM (1990) Radial glial and GFAP-immunoreactive fibers in a region of induced microdysgenesis in the newborn rat neocortex. Soc Neurosci Abstr 16: 1152.

Rosenberg MB, Friedmann T, Robertson RC, Tuszynski M, Wolff JA, Breakefield XO, Gage FH (1988) Grafting genetically modified cells to the damaged brain: restorative effects of NGF expression Science 242:1575-1577.

Rosenberg PA, Dichter MA (1989) Extracellular cAMP accumulation and degradation in rat cerebral cortex in dissociated cell culture. J Neurosci 9:2654-2663

Rosenstein JM (1987) Neocortical transplants in the mammalian brain lack a blood-brain barrier to macromolecules. Science 235:772-774.

Ryder EF, Snyder EY, Cepko CL (1990) Establishment and charactcrization of multipotent neural cell lines using retrovirus vectormediated oncogene transfer. J Neurobiol 21:356-375.

Savio T, Schwab ME (1989) Rat CNS white matter, but not gray matter, is nonpermissive for neuronal cell adhesion and fiber outgrowth. J Neurosci 9:1126-1133.

Snyder EY, Deitcher DL, Walsh C, Arnold-Aldea S, Hartweig EA, Cepko CL (1992) Multipotent neural cell lines can engraft and participate in development of mouse cerebellum. Cell 68:1-20.

Sofroniew MV, Galletly NP, Isacson O, Svendsen CN (1990) Survival of adult basal forebrain cholinergic neurons after loss of target neurons. Science 247:338-342.

Sorensen JC, Zimmer J, Castro AJ (1989) Fetal cortical transplants reduce the thalamic atrophy induced by frontal cortical lesions in newborn rats. Neurosci Lett 98:33-38.

Sotelo C, Alvarado-Mallart RM (1986) Growth and differentiation of cerebellar suspensions transplanted into the adult cerebellum of mice with heterodegenerative ataxia. Proc Natl Acad Sci USA 83:11351139.

Sotelo C, Alvarado-Mallart RM (1987a) Reconstruction of the defective cerebellar circuitry in adult Purkinje cell degeneration mutant mice by Purkinje cell replacement through transplantation of solid embryonic implants. Neuroscience 20:1-22.

Sotelo C, Alvarado-Mallart RM (1987b) Embryonic and adult neurons interact to allow Purkinje cell replacement in mutant cerebellum. Nature 327:421-423.

Sotelo C, Alvarado-Mallart RM, Gardette R, Crepel F (1990) Fate of embryonic Purkinje cells in the cerebellum of the adult "Purkinje cell degeneration" mutant mouse. I. Development of reciprocal graft-host interactions. J Comp Neurol 295:165-187.

Stanfield BB, O'Leary DDM (1985) Fetal occipital cortical neurons transplanted to the rostral cortex can extend and maintain a pyramidal tract axon. Nature 313:135-137.

Temple S (1989) Division and differentiation of isolated CNS blast cells in microculture. Nature 340:471-473.

Tonder N, Sorensen T, Zimmer J, Jorgensen MB, Johansen FF, Diemer NH (1989a) Neural grafting to ischemic lesions of the adult rat hippocampus. Exp Brain Res 74:512-526.

Tonder N, Sorensen T, Zimmer J (1989b) Enhanced host perforant path innervation of neonatal dentate tissue after grafting to axon sparing, ibotenic acid lesions in adult rats. Exp Brain Res 75:483496.

White LA, Whittemore SR (1991) A neuronal cell line derived from medullary raphe. Soc Neurosci Absir 17:571.

Wictorin K, Brundin P, Gustavii B, Lindvall O, Bjorklund A (1990) Reformation of long axon pathways in adult rat central nervous system by human forebrain neuroblasts. Nature 347:556-558.

Wise SP, Jones EG (1976) Organization and postnatal development of the commissural projection of the rat somatic sensory cortex. J Comp Neurol 168:313-343. 